\title{
ESSEX
BUSINESS
SCHOOL
}

Essex Finance Centre

Working Paper Series

\section{Monetary Policy and Corporate Bond Returns}

"Alexandros Kontonikas, Paulo Maio and Zivile Zekaite" 


\title{
Monetary Policy and Corporate Bond Returns*
}

\author{
Alexandros Kontonikas ${ }^{\S} \quad$ Paulo Maio ${ }^{\dagger} \quad$ Zivile Zekaite ${ }^{\ddagger}$
}

October, 2017

\begin{abstract}
We investigate the impact of monetary policy shocks (the surprise change in the Fed Funds rate (FFR)) on excess corporate bonds returns. We obtain a significant negative response of bond returns to FFR shocks. This effect is especially strong in the period before the 200709 financial crisis and for bonds with longer maturity and lower rating. We show that the largest portion of this response is related to higher expected excess bond returns, especially term premia news. Therefore, the discount-rate channel represents an important mechanism through which monetary policy affects corporate bonds. However, the financial crisis has attenuated this effect.
\end{abstract}

Keywords: Corporate Bond Market, Variance Decomposition, Monetary Policy. JEL classification: E44, E52, G10, G12.

\footnotetext{
${ }^{*}$ We would like to thank Alex Kostakis, Chris Florackis, Charles Nolan and conference participants at the 2017 Financial Management Association Annual Meeting, the 2017 World Finance Conference, the Workshop on Corporate Bonds (EM Strasbourg Business School), the 19th Annual Conference of the Swiss Society for Financial Market Research, the Conference on Financial Econometrics and Asset Pricing (Lancaster University Management School), the 5th UECE Conference on Economic and Financial Adjustment (Lisbon School of Economics and Management), the Workshop on Asset Pricing and Corporate Finance (University of Glasgow and Nankai University), the 2016 World Finance and Banking Symposium, and seminar participants at the Department of Business and Management of Webster University (Vienna), Department of Accounting, Economics and Finance of Heriott-Watt University, Department of Economics and Finance of Brunel University, Kent Business School, Kingston Business School and Newcastle University Business School, for helpful comments and suggestions.

${ }^{\S}$ Essex Business School, Finance Subject Group, University of Essex, Colchester, CO4 3SQ, UK, a.kontonikas@essex.ac.uk, 00441206 874569. Corresponding author.

${ }^{\dagger}$ Department of Finance and Statistics, Hanken School of Economics, Arkadiankatu 22, Helsinki, 00101, Finland,paulo.maio@hanken.fi

‡Adam Smith Business School, University of Glasgow, Glasgow, G12 8QQ, z.zekaite.1@research.gla.ac.uk
} 


\section{Introduction}

While the impact of monetary policy actions on the stock and Treasury bond markets has been widely studied, previous research in the area of corporate bonds is considerably less dense. ${ }^{1}$ Given the relevance of debt financing for firms and the size of the market for corporate debt, it is important to understand how monetary policy affects the pricing of corporate bonds. ${ }^{2}$ Especially more so, since the Federal Reserve (Fed) is in the process of normalising monetary conditions, following a prolonged period of ultra-loose monetary policy.

In this paper, we conduct an empirical analysis of the effects of unanticipated monetary policy actions on the contemporaneous returns of corporate bonds. The main contribution of the paper lies on identifying the channels through which monetary policy shocks affect corporate bond returns. In order to get an insight into the observed reaction, we utilise a return decomposition framework that relates current realized unexpected excess bond returns to revisions in expectations ("news") about the future excess bond return (discount rate news or bond premium news) and the short-term interest rate (interest rate news). The decomposition of returns to news about macro-fundamentals and expected risk premia was pioneered in bond market studies by Campbell and Ammer (1993) using Treasury bond returns. The methodology is flexible enough to allow for the incorporation of monetary policy shifts in the analysis. This enables us to decompose the response of corporate bond returns to shocks in the Federal funds rate (FFR) into the effects on each of the two news components. Specifically, according to this present-value model, an increase in FFR has a negative effect on current corporate bond returns, because it leads to an increase in future bond risk premia, short-term interest rates, or a combination of these two effects.

Although monetary policy proxies have been included in studies of corporate bond return predictability and empirical investigation of the determinants of the corporate-government bond yield spread, we are the first to examine the contemporaneous response of corporate bond returns

\footnotetext{
${ }^{1}$ Stock market studies typically find that the contemporaneous response of returns to a monetary tightening shock is negative (Thorbecke, 1997; Bernanke and Kuttner, 2005; Kontonikas and Kostakis, 2013; Maio, 2014). Analyses of Treasuries show that bond yields respond significantly to shifts in the policy rate (Kuttner, 2001; Cochrane and Piazzesi, 2002; Gurkaynak et al., 2005; Hanson and Stein, 2015). The literature on corporate bonds is overall less voluminous, and even thinner with regards to the impact of monetary policy actions. Previous studies tend to focus on two issues - the predictability of corporate bond returns (Fama and French, 1989; Jensen et al., 1996; Baker et al., 2003; Greenwood and Hanson, 2013) and the factors that determine the credit spread (Collin-Dufresne et al., 2001; Elton et al., 2001; Driessen, 2005; Avramov et al., 2007; Gertler and Karadi, 2015; Javadi et al., 2017; Nozawa, 2017). With the exception of a small number of studies that we discuss later in this section, the role of monetary policy actions in general, and policy rate shocks in particular, has been under-explored in the case of corporate bonds.

${ }^{2}$ The U.S. market for corporate debt is the largest in the world. The value of outstanding U.S. corporate debt at the end of 2014 was about 7.8 trillion dollars according to data from the Securities Industry and Financial Markets Association.
} 
to monetary policy shocks and its decomposition into the components of excess bond returns. Our analysis focuses on monetary policy shocks, which are identified by using data on FFR futures contracts (Kuttner, 2001), since anticipated policy actions should be already priced in the bond market. ${ }^{3}$ We use monthly return data on both long-term and intermediate corporate bond indices, each of them associated with three different credit ratings (AAA, AA, and A).

By conducting simple regressions over the 1989.02-2013.12 and 1989.02-2007.07 periods, we obtain a negative and significant response of excess returns on corporate bonds to shocks in FFR prior to the financial crisis. This conclusion remains valid across both medium and longer maturities as well as across different credit ratings. The effect of monetary policy on bond returns is weaker and less significant in the full sample, indicating potential implications of the financial crisis and the subsequent change in Fed policy stance. Similar results are obtained when we examine monetary policy effects on unexpected excess bond returns, which are obtained from a first-order VAR.

With respect to the bond return variance decomposition, for the pre-crisis period we provide evidence that discount rate news constitute the key driving force that explains the response of bond returns to monetary shocks. In other words, the largest share of the contemporaneous negative response of corporate bond returns to monetary policy tightening can be attributed to higher expected excess bond returns (higher bond risk premia). The effects of monetary policy shocks on the expectations of short-term interest rates are relatively small when it comes to explaining the negative effect of interest rate rises on current bond returns. Therefore, the discount rate channel represents an important mechanism through which monetary policy affect corporate bonds. These results are robust across the six bond indices analyzed, however there are some relevant differences across these bond categories. First, the impact of policy changes on bond premia news is larger on longer-maturity compared to intermediate-maturity bonds. Second, the share of bond premia news in the total (absolute) return response tends to be stronger for bonds with higher credit rating.

The results for the full sample that includes the recent financial turmoil (2007-2009) are somewhat different. For this period, across most of the bond indices considered, what explains the negative bond return responses to monetary tightening shocks are positive revisions in future short-term interest rates. The bond premia channel is significantly less relevant when it comes to

\footnotetext{
${ }^{3}$ For example, in anticipation of the increase in the FFR in December 2015, the Economist (December 12, 2015) points out: "If the Federal Reserve does increase interest rates on December 16th, very few investors will be taken by surprise. It will be the most discussed, most anticipated rate rise in history". The use of FFR shocks as a proxy for U.S. monetary policy shifts is well-established in the related literature (Bernanke and Mihov, 1998; Romer and Romer, 2004; Bernanke and Kuttner, 2005).
} 
explaining the impact of the Fed policy on bond returns. These results should be a consequence of two facts originating in the recent financial crisis. First, the significant rise in volatility in corporate bond prices and the widening of credit spreads. Second, the change in Fed policy by adopting a ultra-expansionary stance that led the Fed funds target to attain the zero-lower bound (mixed with the adoption of unconventional policies, which represent new interventions in credit and bond markets). Both of these events likely lead to significant outliers in (i) the relationship between FFR shocks and corporate bond returns and (ii) the estimation of the bond return decomposition. This could explain why the impact of policy shocks on bond premia news is significantly attenuated when we include the most recent period in the sample.

We conduct an extensive sensitivity analysis to our benchmark results. First, we use alternative state vector specifications for the underlying VAR model. Second, we consider higher-order VARs. Third, we use the consol bond formulas to conduct the variance decomposition for returns on long-term corporate bonds. Fourth, we consider an alternative identification scheme for the components of excess bond returns. Fifth, we use lagged FFR shocks as an exogenous variable in the VAR and also employ the methodology suggested by Romer and Romer (2004) to calculate monetary policy shocks. Finally, we account for risk premia in the FFR futures contracts. Overall, our main findings are robust to these robustness checks.

In the last part of the paper, we compute an alternative bond return decomposition, which disentangles bond premia news into one component related to term premia news and another component related with credit premia news. Our findings clearly suggest that the reaction of the corporate bond market to monetary policy shifts is primarily related to risk premium revisions, which in turn are related with the slope of the yield curve (term premia news) rather than related to credit risk (credit premia news). Hence, term premia plays a significantly more important role in driving expected corporate bond returns, at least in what concerns the reaction to monetary policy surprises.

Methodologically, this paper is closely linked to the stock market study of Bernanke and Kuttner (2005), who use a similar monetary policy proxy and decompose the total stock return reaction to monetary policy shocks into the components of realized stock returns. Critically, our paper extends their analysis to corporate bonds and provides additional evidence supporting their insight about an increase in risk premia in response to tight money shocks. Thus, the relation between monetary shocks and future risk premia is not confined to the stock market and also holds in the corporate bond market. ${ }^{4}$ This work is also related to a recent study

\footnotetext{
${ }^{4}$ The study of Jensen et al. (1996) is one of the few papers that examine the relationship between monetary policy and expected corporate bond returns using a predictability framework. They characterise monetary policy
} 
by Gertler and Karadi (2015) who use FFR futures contracts to calculate monetary policy shocks and find that the increase in private credit costs, in response to unexpected tightening, primarily reflects higher risk premia. The focus on this paper, however, is different since we model the impact of monetary policy shocks on corporate bond index portfolio returns and also use a different method to decompose the total return response to interest rate shocks into the unobserved components of excess bond returns. ${ }^{5}$ In related work, Nozawa (2017) decomposes yield spreads for corporate bonds into changing expected returns and changing expectation of credit losses and finds that they are both significant in explaining the variance of credit spreads. Our work differs in three main ways: first, we conduct a decomposition for excess corporate bond returns; second, we focus on high quality (nearly default free) corporate bonds and therefore do not consider a term that reflects credit losses; third, and perhaps more importantly, our paper's emphasis lays on the monetary policy effects on bond risk premia. This work is also related with a broad literature that studies the interaction between macro variables and corporate bond returns (Elton et al., 1995; Bessembinder et al., 2009; Giesecke et al., 2011; Bali and Wen, 2017).

This paper provides additional evidence supporting the significant role that news about expected returns or discount rates play in explaining asset price fluctuations. The primacy of risk premia news is typical in previous return decomposition studies that examine stocks at the market level (Campbell, 1991; Campbell and Ammer, 1993; Bernanke and Kuttner, 2005), but not in studies that analyse Treasury bonds. ${ }^{6}$ The latter tend to identify other components (inflation news) as the key driver of excess bond returns (Campbell and Ammer, 1993; Engsted and Tanggaard, 2007; Kontonikas et al., 2015). Hence, the type of borrower (sovereign versus corporations) seems to play an important role on the reaction of investors to fundamental news. In this particular dimension (i.e., the relative correlation of contemporaneous unexpected excess returns to discount rate news), corporate bonds seem to behave more like stocks, rather than Treasuries. ${ }^{7}$ Thus, our results also contribute towards a better understanding of the similarities using a dummy variable, based on previous changes in the Fed's discount rate, which captures monetary regimes (expansive vs. restrictive cycles) rather than policy shocks. After controlling for the effect of the business conditions variables of Fama and French (1989), they find no evidence for a direct monetary effect on expected returns and only weak evidence for an indirect effect.

${ }^{5}$ The "excess bond premium" that Gertler and Karadi (2015) consider is based upon previous work by Gilchrist and Zakrajsek (2012). Firm-level data is used to calculate the credit spread and then decompose it in two components: a component that captures systematic movements in firm-specific default risk, and a residual component, the excess bond premium, that reflects exposure to corporate credit risk in excess of the compensation for expected defaults.

${ }^{6}$ Moreover, if we move from the market level to individual stocks (or portfolios of stocks) level, cash-flows news become the main component of unexpected excess stock returns (Vuolteenaho, 2002; Maio, 2014).

${ }^{7}$ We also compute the policy responses of the stock market return and its components (discount-rate news, cash-flow news, and interest rate news) for both the full and restricted samples. Our results are qualitatively similar to those obtained for corporate bond returns. Specifically, discount-rate (equity premia) news is the major channel of monetary policy transmission, although the magnitude of this effect has declined after the financial 
and differences that corporate bonds exhibit in comparison to other major asset classes. Apart from informing financial managers about the exposure of corporate bonds to monetary policy and interest rate risk, this line of research also has important implications for monetary policy makers. Financial markets are relevant in several channels of the transmission mechanism of monetary policy (Boivin et al., 2010) and the market for corporate debt, in particular, plays a crucial role in the credit channel (Bernanke and Gertler, 1995).

We now briefly discuss how the risk premium effects of monetary policy actions may be interpreted and rationalised. Bernanke and Kuttner (2005) argue that tight money can have a positive effect on expected returns by increasing the riskiness of firms. Specifically, firm riskiness can increase, in response to an unexpected increase in the FFR, through a rise in the interest burden and the weakening of balance sheets, which can also translate into an increase in the credit spread. ${ }^{8}$ This risk-based explanation is consistent with asset pricing models in which the (innovation) in a short-term interest rate (and specifically, the innovation in $F F R$ ) is a priced risk factor that helps to explain cross-sectional equity risk premia (Brennan et al., 2004; Petkova, 2006; Lioui and Maio, 2014; Maio and Santa-Clara, 2017). In these multifactor models, the interest rate factor earns a negative price of risk, and thus stocks that have negative interest rate factor loading (that is, negative return responses against positive changes in interest rates) earn a higher risk premium, which translates into higher expected stock returns, relative to stocks that are uncorrelated with short-term interest rates. Moreover, stocks with more negative interest rate betas enjoy higher expected returns than stocks with less negative interest rate loadings. In the same vein, corporate bonds with negative interest rate betas earn higher expected returns than bonds with zero loadings on the interest rate factor. Likewise, bonds with more negative interest betas earn higher expected returns than bonds with less negative loadings, which is consistent with our empirical evidence for the pre-crisis sample (larger magnitudes in the total return responses to $F F R$ shocks tend to translate into more positive impacts on expected bond returns).

The paper proceeds as follows. Section 2 describe the data and variables employed in the empirical analysis. In Section 3, we measure the contemporaneous effect of monetary policy crisis.

${ }^{8}$ According to the credit channel theory of monetary policy transmission, the effects of monetary policy shifts on private borrowing costs are amplified through endogenous changes in the external finance premium. The external premium reflects the cost differential between funds raised externally (by issuing equity or debt) and funds generated internally, and is inversely related to the creditworthiness of the borrower. In line with this theory's prediction, apart from Gertler and Karadi (2015), a number of other studies demonstrate empirically that the bond credit spread increases when monetary policy tightens (Avramov et al., 2007; Chun et al., 2014; Cenesizoglu and Essid, 2012). In a recent study, Javadi et al. (2017) find that credit spreads mostly respond to expansionary policy actions (by narrowing), while tightening only affects spreads when default and inflation risks are ex ante high. 
shocks in corporate bond returns. Section 4 shows the results for a VAR-based decomposition of the total bond return response to shocks in FFR into the effects on the two components of excess bond returns. Section 5 provides a sensitivity analysis, while Section 6 shows the results from an alternative decomposition. Section 7 concludes.

\section{Data and variables}

\subsection{Corporate bond returns and state variables}

U.S. corporate bond indices constructed by Barclays are used to calculate corporate bond returns. The Barclays indices, formerly maintained by Lehman Brothers, are often used in academic studies to represent the U.S. corporate bond market and represent standard benchmarks for managing bond portfolios in the asset management industry (Sangvinatsos, 2005; Abhyankar and Gonzalez, 2009). They capture the total holding period return, by reflecting capital gains and coupon payments, and incorporate USD-denominated, fixed-rate, taxable bonds that are publicly issued by both U.S. and non-U.S. industrial, utility, and financial firms (minimum issue size is USD 250 million). The indices are value-weighted and rebalanced at the end of each month. All component bonds are marked by Barclays market-makers at the middle and end of each month. ${ }^{9}$ Bonds with fixed-to-floating coupon rate are only included during their fixed-rate term, while inflation-linked bonds, bonds with equity type features (e.g., warrants and convertibles), and bonds with less than one year to maturity are excluded. Finally, in addition to bullet bonds, the indices include bonds with embedded put and call options and sinking fund provisions. The inclusion of bonds with embedded options in the Barclays indices is a non-trivial matter when it comes to analysing the impact of monetary policy actions on corporate bond returns. Due to changes in the value of the option, the price of such bonds is less sensitive to interest rate changes, as opposed to comparable option-free bonds. The incorporation of callable and putable bonds in the analysis should generally attenuate the reaction of corporate bond returns to the interest rate shocks that the Fed initiates. Hence, it is likely that the monetary policy elasticities that we capture in the next section would have been stronger in the absence of bonds with embedded options. ${ }^{10}$

\footnotetext{
${ }^{9}$ The use of model/matrix-based pricing is limited to a minority of the bonds that enter the Barclays indices. Specifically, up to 3,000 actively traded benchmark corporate bonds are priced by Barclays Capital traders on a daily basis, while the remaining less liquid bonds are priced using an Option Adjusted Spread model or issuer curve that is generated using these actively quoted benchmark bonds. For more details on the construction of the Barclays indices see Goltz and Campani (2011) and the information that accompanied the rebranding of the Lehman indices in November 2008, available at https://index.barcap.com/download?rebrandingDoc.

${ }^{10}$ Callable bonds constitute the majority of bonds with embedded options. Their share in the market for corporate bonds has fluctuated significantly over time. It was very high until the late 1980s, decreasing to a
} 
The six Barclays indices that we use represent portfolios of investment-grade corporate bonds with different maturity and credit rating characteristics. Specifically, we consider indices of longterm $(L)$ and intermediate $(I)$ maturity corporate bonds with AAA, AA, and A ratings. Bond ratings are assigned using the middle rating of Moodys, SP and Fitch, or the lowest rating if only two ratings are available. Bonds included in the intermediate maturity indices have maturity of one to less than ten years, while long-term indices are based on bonds with maturity of ten years and more. Monthly data on the Barclays indices (end of month observations) is collected over the period 1989.01-2013.12 from Datastream. The bond data sample commences during the early years of the Great Moderation period, while its latter part contains the recent global financial crisis and its aftermath. ${ }^{11}$ The empirical analysis is conducted over both the full sample period and a shorter sample that ends in July 2007, that is, prior to the onset of the recent financial crisis. This will allow us to isolate the potential effects of the crisis and the resulting ultra-loose monetary stance on the variance decomposition of bond returns and the relationship between monetary actions and bond returns. ${ }^{12}$

To compute monthly excess corporate bond returns $\left(x_{n}\right)$, we take the first difference in the log of the Barclays index and subtract the continuously compounded one-month Treasury bill rate (y) that we obtain from the Centre for Research in Security Prices. ${ }^{13}$ The descriptive statistics in Table 1 indicate that both the mean and standard deviation of excess returns on long-term corporate bonds are higher than those of intermediate maturity bonds. As the rating declines, average returns tend to increase (especially among long-term bonds); removing the crisis period, however, eliminates this effect. These patterns are also consistent with the graphical evidence in Figure 1, which plots the (normalised) level of the Barclays indices for A and AAA long-term and intermediate maturity bonds: prior to the crisis lower quality bonds did not outperform higher quality bonds. ${ }^{14}$ For all indices under investigation, the standard deviation of excess returns is lower in the pre-crisis period, as opposed to the full sample, highlighting the volatile

historical low by the mid-1990s, and then increasing again over the past decade. As Gilchrist and Zakrajsek (2012) argue, limiting the sample to non-callable corporate bonds would significantly limit the available timespan. Nozawa (2017) makes the same argument to support the inclusion of callable bonds in the sample and finds that his main results are not driven by the callability feature.

${ }^{11}$ By the mid-1980s, Volcker's disinflation was largely accomplished with inflation declining sharply from $10 \%$ (per annum) at 1980 to $3 \%$ at 1983 . This development allowed interest rates to decline and ushered the Great Moderation era that was characterised by lower macroeconomic volatility.

${ }^{12}$ The start of the financial crisis is dated to August 2007 when doubts about financial stability emerged and the first major central bank interventions in response to increasing interbank market pressures took place (Brunnermeier, 2009; Kontonikas et al., 2013). Following that, on September 2007 the Fed proceeded to the first major FFR cut $(0.5 \%)$ since 2003 , initiating a long cycle of monetary expansion.

${ }^{13} n$ denotes the average maturity of the bond index.

${ }^{14}$ Moreover, while in the full sample for intermediate maturity bonds lower rating is associated with higher volatility of bond returns, for long-term bonds the opposite is true. However, this does not hold in the restricted sample. 
nature of returns during the recent bad times. The full sample maximum and minimum values of excess bond returns, shown in Table 1-Panel A, in almost all cases materialise at the peak of the financial crisis, between September and December of 2008.

Table 2 reports the correlation coefficients between excess corporate bond returns across different maturities and ratings. Three stylised facts can be identified. First, correlations are stronger between bond returns of similar maturity. For example, while the full sample correlation between long-term AAA and AA excess bond returns is 0.92 , it declines to 0.79 for when the latter are replaced with intermediate maturity AA returns. Second, the magnitude of the correlation coefficients increases when the bonds that we consider are more alike in terms of credit quality. For instance, the full sample correlation coefficient between intermediate maturity AAA and AA excess bond returns is 0.94, dropping to 0.90 when we use, instead of the latter, intermediate maturity A returns. Third, correlations are overall stronger during the pre-crisis period.

In addition to corporate bond excess returns, the Treasury bill rate, and a proxy for monetary policy shocks, the empirical analysis conducted in the following sections requires data on several other variables. The default spread (def) is equal to the Moodys seasoned Baa corporate bond yield minus the ten-year Treasury bond yield. The term spread (term) represents the difference between the ten-year Treasury bond yield and the one-month Treasury bill rate. ${ }^{15}$ The Treasury bond yield and Moody's BAA yield data are obtained from the Federal Reserve Bank of St Louis database (FREDII).

\subsection{Monetary policy shocks}

Monetary policy conducted during the period that we investigate is characterised by targeting of the Fed Funds rate (FFR), the interest rate on overnight loans of reserves between banks, and also by increasing transparency (Bernanke and Blinder, 1992; Bernanke and Mihov, 1998; Romer and Romer, 2004). We proxy monetary policy shocks by isolating the unexpected component of changes in the FFR. To do so, we use data on FFR futures and the methodology employed by Kuttner (2001). This market-based proxy of policy shocks has been widely used in the literature that examines the impact of monetary policy on stocks and bonds (Bernanke and Kuttner, 2005; Bredin et al., 2010; Cenesizoglu and Essid, 2012; Kontonikas et al., 2015). The month $t+1$ monetary policy shock $(M P)$ is calculated as follows:

\footnotetext{
${ }^{15}$ All the variables that we use are stationary according to the results from Augmented Dickey-Fuller and Phillips Perron unit root tests (results available upon request).
} 


$$
M P_{t+1}=\frac{1}{D} \sum_{d=1}^{D} i_{t+1, d}-f_{t, D}^{1},
$$

where $i_{t+1, d}$ denotes the target FFR on day $d$ of month $t+1$ and $f_{t, D}^{1}$ is the rate corresponding to the one-month futures contract on the last $\left(D^{t h}\right)$ day of month $t$. The implied futures rate is 100 minus the contract price. ${ }^{16}$ The futures data, sourced from Bloomberg, commences on 1989 with the first observation on MP corresponding to 1989.02. The FFR data are obtained from the FREDII database.

Figure 2 plots our measure of monetary policy shocks. Some of the largest unexpected changes in the FFR occurred during, or near, periods of economic slowdown. These pronounced shocks were typically of monetary expansionary nature, that is, associated with negative values of the $M P$ indicator. Nevertheless, the recent major recession and financial crisis period witnessed a large positive realisation of $M P$ in November 2008. This reflects the fact that Fed kept the target rate constant at $1 \%$ throughout November 2008, while market participants expected further decline, following two rate decreases in October 2008. The final cut, which brought the FFR down to the zero lower bound, took place in December 2008. Ever since, and until the end of the sample, there were no rate changes and the volatility of FFR shocks dies out. This is not surprising considering the effort that the Fed had put in assuring the public and financial markets about its intention to keep the policy rate at near zero in the future. ${ }^{17}$ The Fed's aggressive interest rate response to the financial crisis was supplemented with liquidity provision facilities and large scale purchases of mainly Treasury bonds and agency mortgage backed securities. The bond market effects of the Fed's unconventional policies are analysed in previous studies (Gagnon et al., 2011; Christensen and Rudebusch, 2012; Wright, 2012; Krishnamurthy and Vissing-Jorgensen, 2011) and are beyond the scope of this paper that focuses on conventional FFR-based policy shocks.

The monetary policy indicator is included as an exogenous variable in the VAR model of Section 4 below. The exogeneity assumption would not be valid if the Fed responds contempo-

\footnotetext{
${ }^{16}$ The 30-day Federal Funds Futures contracts that we use are traded on the Chicago Board of Trade. The futures settlement price is based upon the monthly average effective FFR which follows very closely the target rate (Bernanke and Kuttner, 2005; Fama, 2013). It should be noted that measuring surprise changes in terms of the average FFR may understate the magnitude of policy surprises. The time-aggregation issue is analysed in Evans and Kuttner (1998). Cenesizoglu and Essid (2012) find that adjusting for the the risk premium in Federal Funds contracts, by using the procedure of Piazzesi and Swanson (2008), makes no difference when analysing the impact of FFR shocks on corporate bond yield spreads.

${ }^{17}$ Initially, the language was qualitative with post-meeting statements of the Federal Open Market Committee (FOMC) including phrases such as the FFR will remain near zero for "an extended period" (FOMC statement of March 18, 2009). It then evolved to date-based guidance, specifying future dates such as "at least through mid-2015" (September 13, 2012). Finally, a threshold-based approach was adopted linking the first rate increase to developments in inflation and unemployment.
} 
raneously to developments in the market for corporate bonds (reverse feedback) and/or if the Fed and corporate bonds jointly and contemporaneously respond to economic news (simultaneity). With respect to reverse feedback, while modifications of the Taylor rule have been recently proposed, whereby the Fed responds to measures of financial stress including credit spreads (Taylor, 2008; Curdia and Woodford, 2010), these rules refer to a systematic response involving actual and expected FFR changes, as opposed to unexpected changes (Cenesizoglu and Essid, 2012). The use of shocks is crucial not only to ameliorate endogeneity concerns, but also because anticipated policy actions should be already priced in the bond market.

In order to examine whether FFR shocks react to economic news we follow Bernanke and Kuttner (2005) and regress these shocks on variables that capture surprises in nonfarm payrolls, industrial production growth, retail sales growth, core and headline CPI inflation,

$$
M P_{t+1}=\alpha+\boldsymbol{\beta}^{\prime} \boldsymbol{\psi}_{t+1}+\varepsilon_{t+1}
$$

where $\boldsymbol{\psi}$ denotes the vector of economic indicators. Surprises are calculated as the difference between the actual value that was released for a given key macroeconomic variable and the median forecast from Reuters Economic Polls. Table 3 reports the results. ${ }^{18}$ We do not find a significant contemporaneous monetary policy response to macroeconomic surprises: only in one case (industrial production in the estimation for the full sample) is there a marginally significant slope (10\% level). Moreover, in the robustness checks analysis in Section 5, we address the potential endogeneity issue directly and we find that the main results hold. Hence, the exogeneity assumption should not be significantly restrictive in our case.

\section{Monetary policy effects on corporate bond returns: a simple regression approach}

In this section, we estimate the contemporaneous reaction of monthly excess corporate bond returns to shocks in the Fed funds rate (FFR). We start with the following baseline regression model:

$$
x_{n, t+1}=\gamma_{0}+\gamma_{1} M P_{t+1}+u_{t+1},
$$

where $x_{n}$ denotes excess returns on the Barclays corporate bond index with average maturity

\footnotetext{
${ }^{18}$ Due to data availability on the macroeconomic surprises, the sample period for these regressions commences in 1991.10.
} 
of $n, M P$ represents unexpected changes in the FFR, and $u$ denotes the component of excess returns that is not explained by monetary policy shocks.

The model is estimated by ordinary least squares, for each of the six Barclays indices that we consider, that is, long-term and intermediate maturity with AAA, AA, and A ratings. The $t$-statistics are calculated using heteroskedasticity-consistent standard errors (White, 1980). The results in Table 4 show that the slope coefficient, $\gamma_{1}$, exhibits a negative sign, albeit the fullsample estimation indicates significance (at the 5 or $10 \%$ level) only for the intermediate maturity bonds. However, in the pre-crisis sample, the effect of unexpected FFR changes is strongly significantly (1\% level) negative across all ratings and maturities, thus indicating that excess corporate returns respond negatively to a tightening shock. In the restricted sample, he responsiveness of long-term corporate bond returns to monetary policy shocks is stronger in comparison to that of intermediate maturity bonds, as indicated by the magnitudes of the slopes. Moreover, there is a tendency for the reaction of returns to $M P$ to increase in magnitude, albeit not always monotonically, as we move from higher grade towards lower grade bonds. Hence, lower rating bonds are more responsive to monetary shocks. The weaker significance levels that we identify in the full sample can be attributed to the incorporation of the financial crisis in the estimation window. As discussed in Section 2.1, the volatility of bond returns increased significantly during that period of financial turmoil, leading to some extreme observations. Moreover, the financial crisis lead the Fed to adopt a very expansionary monetary policy with FFR reaching the zero-lower bound. These two forces combine to originate a deterioration in the fit of the empirical model and the statistical significance of the regression slopes. In fact, the $R^{2}$ estimates are significantly larger in the restricted sample across all six bond indices.

We proceed by adding several business conditions controls to the regression above in order to assess the robustness of the baseline findings. These controls include two important indicators of business conditions proposed by Fama and French (1989), the default spread (def) and the term spread (term). ${ }^{19}$ We also include the one-month Treasury bill rate $(y)$. Thus, the following augmented regression model is estimated:

$$
x_{n, t+1}=\gamma_{0}+\gamma_{1} M P_{t+1}+\gamma_{2} d e f_{t+1}+\gamma_{3} t e r m_{t+1}+\gamma_{4} y_{t+1}+v_{t+1},
$$

The results in Table 5 indicate that, with the exception of the default spread (in the precrisis sample), business conditions proxies tend not to be statistically significant in terms of

\footnotetext{
${ }^{19}$ These variables are also used as risk factors that help to price cross-sectional bond risk premia (see Fama and French (1993) and Gebhardt et al. (2005)).
} 
explaining contemporaneous excess bond returns. Furthermore, the main findings from the baseline estimations remain robust. In the full sample, the impact of FFR shocks on excess bond returns is negative and statistically significant only in the case of intermediate maturity bonds, which is consistent with the evidence from the univariate regressions discussed previously (although there is stronger significance (1\% level) in comparison to the univariate regressions). When the financial crisis and its aftermath are excluded from the sample period, we find that the monetary policy effect is always highly significant ( $1 \%$ level), similarly to the univariate regressions. As the rating declines and maturity increases, the sensitivity of bond returns to FFR surprises tends to rise, also in line with the results for the single regressions. Overall, the empirical findings in this section are indicative of a negative contemporaneous reaction of excess corporate bond returns to monetary tightening shocks.

\section{Monetary policy effects on corporate bond returns: a VAR- based approach}

In this section, we use an empirical framework that decomposes corporate bond excess returns to their fundamental components in an effort to explain the negative reaction of bond premia to monetary policy shocks, documented in the last section.

\subsection{Components of realized excess bond returns}

Modifying the zero-coupon bond framework of Campbell and Ammer (1993) for the case of coupon paying bonds, we can decompose current period unexpected excess bond returns into news about future excess bond returns and short-term interest rates:

$$
\tilde{x}_{n, t+1}=\left(E_{t+1}-E_{t}\right)\left[-\sum_{j=1}^{n-1} \rho^{j} x_{n-j, t+1+j}-\sum_{j=1}^{n-1} \rho^{j} y_{t+1+j}\right]=-\tilde{x}_{x, t+1}-\tilde{x}_{y, t+1},
$$

where $\tilde{x}_{n, t+1} \equiv\left(E_{t+1}-E_{t}\right) x_{n, t+1}$ represents the unexpected one-period log return on a $n$ period bond (or equivalently a bond index with an average maturity of $n$ periods) in excess of the continuously compounded one-period nominal risk-free rate; $\tilde{x}_{x, t+1}$ denotes revisions in expectations regarding future excess bond returns (discount rate news); and $\tilde{x}_{y, t+1}$ denotes revisions in expectations about the future log nominal short-term risk free rate (interest rate news). ${ }^{20}$ The intermediate maturity Barclays corporate bond index has an average maturity

\footnotetext{
${ }^{20}$ In Appendix A, we provide more details on the derivation. For a decomposition of consol bonds, see Engsted and Tanggaard (2001) and Abhyankar and Gonzalez (2009).
} 
of 5 years, while that of the long-term index is 24 years. Hence, for intermediate maturity bonds we set $n=60$ months, while for long-term bonds $n=288 . \rho$ is the linearization constant, a number marginally smaller than one, which is linked to the average yield to maturity of each bond index. ${ }^{21}$

Equation (5) is a dynamic accounting identity that arises from the definition of bond returns and imposes internal consistency on expectations. It is not a behavioural model containing economic theory and asset pricing assumptions and implications. The decomposition implies that negative unexpected excess bond returns must be associated with increases in expected future excess returns during the life of the bond, rises in expected future short-term interest rates, or a combination of these two effects. We do not include a term associated with default losses, as in Nozawa (2017), since our empirical analysis focuses on high quality corporate bonds. Specifically, for the AAA, AA, and A rating categories under consideration the historical average default rates are almost zero (see Table 3 in Standard\&Poors, 2015).

From Equation (5), it follows that the total variance of unexpected excess bond returns can be decomposed into the sum of the two variances plus the covariance term:

$$
\operatorname{Var}\left[\tilde{x}_{n, t+1}\right]=\operatorname{Var}\left[\tilde{x}_{x, t+1}\right]+\operatorname{Var}\left[\tilde{x}_{y, t+1}\right]+2 \operatorname{Cov}\left[\tilde{x}_{x, t+1}, \tilde{x}_{y, t+1}\right]
$$

In order to evaluate the relative importance of discount rate news and interest rate news, we normalise each of the variance and covariance terms in Equation (6) by the total variability of excess returns. The delta method is used to calculate the standard errors for the weights of the terms of the variance decomposition since these represent nonlinear functions of the estimated VAR parameters (see Campbell and Ammer, 1993; Barr and Pesaran, 1997; Bernanke and Kuttner, 2005).

The implementation of the decomposition requires empirical proxies for the unobserved components of excess bond returns. Following Campbell and Ammer (1993), we link these multiperiod expectations to the stationary dynamics of a vector autoregressive model (VAR). Specifically, a first-order VAR is employed, which contains excess bond returns, the one-month Treasury bill rate, and other variables that help to forecast changes in bond premia:

$$
\mathbf{z}_{t+1}=\boldsymbol{\theta}+\mathbf{A} \mathbf{z}_{t}+\mathbf{w}_{t+1}
$$

\footnotetext{
${ }^{21}$ We set $\rho=\frac{1}{1+\overline{Y_{n}}}$, where $\overline{Y_{n}}$ is the average yield to maturity of a given bond index. The average value of $\rho$ used in the estimations is 0.9946 , ranging from 0.9939 in the case of long-term A bonds to 0.9952 for intermediate maturity AAA bonds. These values are based upon the full sample information. We also calculated the corresponding $\rho$ using pre-crisis data and used these values for pre-crisis estimations. The results remain largely unchanged and are available upon request.
} 
where $\boldsymbol{\theta}$ is a vector of intercept terms, $\mathbf{z}_{t}$ is a vector of endogenous state variables, $\mathbf{A}$ denotes a matrix of VAR parameters, and $\mathbf{w}_{t+1}$ is a vector of forecasting residuals. In the benchmark VAR the state vector is given by $\mathbf{z}_{t+1}=\left[x_{n, t+1}, d e f_{t+1}, t e r m_{t+1}, y_{t+1}\right]^{\prime}$, where all the variables are defined as in Section 3.

The forecast errors and the estimated parameters from the VAR model can be used to compute unexpected excess bond returns and the two news components identified in Equation (6) as follows:

$$
\begin{gathered}
\tilde{x}_{n, t+1} \equiv x_{n, t+1}-E_{t}\left[x_{n, t+1}\right]=\mathbf{s}_{1}^{\prime} \mathbf{w}_{t+1} \\
\tilde{x}_{x, t+1} \equiv\left(E_{t+1}-E_{t}\right) \sum_{j=1}^{n-1} \rho^{j} x_{n-j, t+1+j}=\mathbf{s}_{1}^{\prime}(\mathbf{I}-\rho \mathbf{A})^{-1}\left(\rho \mathbf{A}-\rho^{n} \mathbf{A}^{n}\right) \mathbf{w}_{t+1} \\
\tilde{x}_{y, t+1} \equiv\left(E_{t+1}-E_{t}\right) \sum_{j=1}^{n-1} \rho^{j} y_{t+1+j}=-\tilde{x}_{n, t+1}-\tilde{x}_{x, t+1}
\end{gathered}
$$

where $\mathbf{s}_{1}^{\prime}$ is a selection vector that assigns the first element of the state vector to 1 , and $\mathbf{I}$ is the identity matrix.

Equation (8) shows that unexpected excess bond returns represent the residuals from the VAR forecasting model for excess returns. Discount rate news are computed directly from the VAR estimates using Equation (9). Interest rate news are the residual component, that is, we employ Equation (10) to compute them using the dynamic accounting identity and the estimate of discount rate news. This procedure is in line with previous studies that conduct bond returns' decompositions (Engsted and Tanggaard, 2001; Abhyankar and Gonzalez, 2009; Bredin et al., 2010). In the robustness checks section, we show that our results are not sensitive to an alternative identification scheme where discount rate news become the residual component of the bond premium decomposition. We should also note that some modelling noise may be present since the Barclays indices are rebalanced to maintain their specified maturity, while the return decomposition in Equation (5) implies that maturity shrinks as time passes and $j$ increases (Engsted et al., 2012). Chen and Zhao (2009) argue that such modelling noise is not likely to be empirically important. In the robustness analysis, we also implement a decomposition for long-term bonds using the formulas for consol bonds, where the problem of shrinking maturity does not arise, and show that our results do not change in a significant way.

The VAR model that is used to extract news is assumed to contain all relevant information that investors may have when forming expectations about the future. If investors have additional information that is not present in the state vector, the relative importance of the residual 
component may be overstated. ${ }^{22}$ The presence of the default spread and term spread in the state vector is consistent with previous work (Chen and Zhao, 2009; Keim and Stambaugh, 1986; Fama and French, 1989; Greenwood and Hanson, 2013). ${ }^{23}$ In the robustness analysis, we show that our baseline findings are robust to the incorporation of additional macro-financial predictor variables in the VAR state vector.

Table 6 presents the estimates of the excess return forecasting equation in the benchmark VAR for the six Barclays indices. The results can be summarised as follows. First, the one-month ahead forecasting power of the VAR is quite reasonable. Apart from the long-maturity AAA bond index (with an explanatory ratio below $2 \%$ ), the adjusted $R^{2}$ values lie within the range of $3.7-7.2 \%$ in the full sample estimation, which is in line with previous evidence from bond predictability studies. In the pre-crisis sample, the amount of predictability for long-maturity bonds (AA and A indices) is significantly smaller, yet for intermediate bonds the corresponding range in explanatory ratios is between $4.6 \%$ and $5.6 \% .{ }^{24}$ Hence, the forecasting power tends to be higher in the case of intermediate maturity bonds and tends to decline with the bond rating (albeit this second effect is less clear in the restricted sample). Second, with the exception of the default spread, which is only occasionally significant ( $10 \%$ level) in the full sample estimation, the other two predictors are performing quite well in terms of predicting bond risk premia. In agreement with Chen and Zhao (2009) and Baker et al. (2003), we find that future excess bond returns are positively related to the current short-term interest rate and the term spread. Third, long-term bonds exhibit stronger sensitivities to these two predictors (as indicated by the respective slopes) in comparison to intermediate maturity bonds, while the pattern is less clear when we move from higher to lower credit rating. Fourth, there is relevant time-series momentum (positive auto-correlation) for the returns of middle-maturity bonds. ${ }^{25}$

The variance decomposition results are shown in Table 7. The key finding is that across bonds with different maturities and credit ratings, discount rate news typically constitute the major component of shocks in current excess bond returns. More specifically, the shares of

\footnotetext{
${ }^{22}$ Campbell and Ammer (1993) point out that the sign of the possible bias is uncertain since it will depend on the covariances between state variables and any omitted variables.

${ }^{23}$ Baker et al. (2003), Abhyankar and Gonzalez (2009), and Lin et al. (2017) add inflation and/or the real interest rate in the list of potential predictors.

${ }^{24}$ This level of fit compares favorably with similar studies (based on multiple regressions) of one-month ahead predictability of the stock market return (Goyal and Santa-Clara, 2003; Campbell and Vuolteenaho, 2004; Welch and Goyal, 2008; Maio and Santa-Clara, 2012; Maio, 2013a; Maio, 2013b).

${ }^{25}$ The estimated VARs are dynamically stable since no root lies outside the unit circle. The results from the forecasting equations of the other variables are available upon request. In short, they indicate that the short-term interest rate is predicted by the default spread, the term spread, and its own lag, with a high AR(1) coefficient. The default spread is a highly persistent process. The term spread is very persistent too, but also related to the lagged default spread. The adjusted $R^{2}$ values for the default spread and term spread regressions vary between $82 \%$ and $94 \%$.
} 
bond premia news vary between 55\% (for long-term AAA bonds) and 107\% (for intermediate AA bonds) in the full sample, while the range in the restricted sample is between $85 \%$ (for long AAA and A bonds) and 107\% (intermediate AA bonds). Moreover, most of these point estimates are statistically significant (the sole exception is the case of intermediate A bonds in the full sample in which case the estimated weight is not significant at the $10 \%$ level ). These weights also tend to be larger for intermediate relative to long maturity bonds in both samples. Yet, with regards to the relationship between discount rate shares and credit ratings the results are not consistent over time: while in the full sample the weights tend to decrease with credit rating (although not monotonically), there is a less clear pattern over the restricted sample. We can also conclude that the shares of discount rate news tend to be larger in the shorter sample in comparison to the full sample.

Across the board, interest rate news assumes less importance than bond premia news. For example, the corresponding weights in the pre-crisis period vary between $10 \%$ (long AAA bonds) and $44 \%$ (intermediate AA bonds). The shares associated with interest rate news are larger in the full sample, ranging between $21 \%$ (long A bonds) and $71 \%$ (intermediate AA bonds), however these estimates are still clearly below the corresponding shares for bond premia news. Moreover, several estimates for the share of interest rate news are not significant at the $10 \%$ level. On the other hand, although the covariance term between interest rate news and discount rate news appears relatively sizeable for some categories of bonds, they are always statistically insignificant.

In sum, our results for corporate bonds strongly support the importance of discount rate news, as a driver of the total variability of returns, in agreement with studies that conduct variance decomposition for stocks at the market level (Campbell, 1991; Campbell and Ammer, 1993; Bernanke and Kuttner, 2005; Maio, 2014; Maio and Philip, 2015). On the other hand, previous studies on Treasuries find that inflation news is the main component of unexpected excess bond returns (Campbell and Ammer, 1993; Engsted and Tanggaard, 2007; Kontonikas et al., 2015). These results provide additional evidence on the distinct behavior of Treasury and corporate bond returns.

\subsection{Explaining the impact of monetary policy shocks on bond returns}

In order to explain the source of the corporate bond market's reaction to monetary policy shocks, we estimate the effect of these shocks in unexpected excess bond returns and also their three components. To do so, we follow Bernanke and Kuttner (2005) and include unexpected FFR 
changes as an exogenous variable in the VAR model:

$$
\mathbf{z}_{t+1}=\boldsymbol{\theta}+\mathbf{A} \mathbf{z}_{t}+\phi M P_{t+1}+\boldsymbol{\omega}_{t+1}
$$

where $\phi$ is a vector that includes the state variables response parameters to contemporaneous monetary policy shocks. The original VAR error vector $\left(\mathbf{w}_{t+1}\right)$ is essentially decomposed in a component related to the monetary policy actions, $\phi M P_{t+1}$, and a component related to other information, $\boldsymbol{\omega}_{t+\mathbf{1}}$. Following Bernanke and Kuttner, 2005, we proceed by estimating the original VAR model to obtain estimates of $\mathbf{A}$ and then regress the VAR residuals vector on monetary policy shocks in order to estimate $\phi$. The monetary policy impact on the contemporaneous unexpected excess bond returns, discount rate news, and interest rate news can be calculated using Equations (12)-(14), respectively:

$$
\begin{gathered}
\tilde{x}_{n, t+1}^{M P}=\frac{\partial \tilde{x}_{n, t+1}}{\partial M P_{t+1}}=\mathbf{s}_{1}^{\prime} \boldsymbol{\phi}, \\
\tilde{x}_{x, t+1}^{M P}=\frac{\partial \tilde{x}_{x, t+1}}{\partial M P_{t+1}}=\mathbf{s}_{1}^{\prime}(\mathbf{I}-\rho \mathbf{A})^{-1}\left(\rho \mathbf{A}-\rho^{n} \mathbf{A}^{n}\right) \boldsymbol{\phi}, \\
\tilde{x}_{y, t+1}^{M P}=\frac{\partial \tilde{x}_{y, t+1}}{\partial M P_{t+1}}=-\tilde{x}_{n, t+1}^{M P}-\tilde{x}_{x, t+1}^{M P} .
\end{gathered}
$$

Thus, the response of excess bond returns and their components to monetary policy shocks depends both on $\phi$ and the dynamics of the VAR through the VAR coefficient matrix, A. As in Bernanke and Kuttner (2005), the delta method is used to compute standard errors for these responses to monetary shocks.

Table 8 presents the results. In the full sample, the total response of unexpected excess bond returns to shocks in FFR is negative and almost always statistically significant. The sole exception is for long-term AAA bonds, in which case the negative slope is not significant at the $10 \%$ level. Excluding the recent financial crisis and its aftermath, the effect of policy shocks becomes strongly significant (1\% level) across all ratings and maturities. These results imply that unexpected excess bond returns respond negatively to a monetary tightening shock and are consistent with the results for excess bond returns (univariate regressions) in Section 3 (the main difference being that the significance of the monetary responses improves sharply in the full sample). Mirroring the results from the univariate regression estimates, in the pre-crisis sample the monetary policy effect on long-term corporate bond returns is always stronger (as indicated by the magnitudes of the respective slopes) than the effect on intermediate maturity bonds. However, for the full sample we get an opposite relation. Furthermore, in both samples 
the total response of unexpected excess bond returns to policy shocks increases in magnitude as the credit rating deteriorates (again, these results are in line with the univariate regression analysis in Section 3).

Moving on to the reaction of the components of excess bond returns, we start the discussion with the findings for the pre-crisis period, which are more clear-cut. The results show that the effect of monetary policy shocks is basically explained though the discount rate news channel. For all bond indices, tightening shocks negatively affect contemporaneous unexpected excess corporate bond returns through an increase in expected bond returns. In all cases the estimates of $\widetilde{x}_{x, t+1}^{M P}$ are strongly significant (1\% level), while the policy impact on interest rate news is not statistically significant in any case. The share of bond premia news in the total (absolute) return response tends to be stronger for bonds with higher credit rating. In the intermediate maturity group, for example, discount rate news contribute towards $86 \%(1.96 / 2.29)$ of the response of excess returns on AAA bonds to a policy shock, while the corresponding figure for A bonds is $66 \%(1.87 / 2.82)$. In the case of long-maturity AAA and A bonds the corresponding estimates are $92 \%$ and $79 \%$, respectively. ${ }^{26}$ We also observe that the estimates of $\widetilde{x}_{x, t+1}^{M P}$ are larger among long maturity in comparison to intermediate maturity bonds, mirroring the direction observed in the magnitudes of the total return responses. ${ }^{27}$ This dominant role of discount rate news in explaining the response of excess corporate bond returns to monetary shocks is in agreement with the evidence of Bernanke and Kuttner (2005) for the stock market.

With regards to the full sample results, we note that the incorporation of the financial crisis in the estimation window leads to much less precise estimates of discount rate news reaction to policy shocks. Indeed, only for the highest rating category (long and intermediate AAA bonds) are the bond premia responses statistically significant. In contrast with the results for the restricted sample, the monetary effects on interest rate news $\left(\widetilde{x}_{y, t+1}^{M P}\right)$ are statistically significant for most bond categories (the exceptions are the long AAA and AA indices). It turns out that for most bond indices the largest magnitudes (and shares) of responses are associated with interest rate news, particularly among intermediate maturity bonds. Out of the six bond indices only in one case (long AAA bonds) does the discount-rate channel dominate the interest rate channel when it comes to explain the total return loading on monetary shocks (in the case of long AA bonds both shares have a similar magnitude and are statistically insignificant). Hence, in the full

\footnotetext{
${ }^{26}$ In the case of intermediate maturity bonds, the relationship between credit quality and the share of bond premia news in the total return response is monotonic.

${ }^{27}$ We should note that larger weights of bond premia news on excess bond returns (as calculated in Table 7) does not necessarily imply larger estimates of $\widetilde{x}_{x, t+1}^{M P}$. For example, long-maturity bonds tend to have smaller shares of $\operatorname{Var}\left[\widetilde{x}_{x}\right]$ (see Table 7), despite having larger policy effects on bond premia news than middle-maturity bonds.
} 
sample period we find that interest rate news outweigh discount-rate news in terms of explaining the effect of monetary shocks on most corporate bond returns and this trend is especially notable among lower rating bonds. This decline in the importance of the bond premia channel should be related with the 2007-09 financial crisis. Indeed, there was a significant spike in the volatility of bond returns during the recent financial crisis, especially relevant among lower-rating bonds. This event, combined with the very expansionary monetary policy that forced $F F R$ to reach the zero-lower bound, are the likely causes of the smaller effect of policy shocks on bond premia news. More specifically, both events should have contributed to the decline in the total bond return responses to monetary policy shocks. On the other hand, the increased volatility in credit markets (that affects not only the bond returns but also some of the VAR state variables) is likely the main cause behind the smaller weight of discount rate news (over total bond returns) and the smaller correlation between bond premia news and policy shocks registered over the full sample. ${ }^{28}$

Overall, the VAR-based results strongly favour discount rate news in being the key driver of the response of excess bond returns to monetary policy shocks in the pre-crisis period, with monetary tightening negatively affecting contemporaneous returns through higher expected returns. However, the results also indicate that recently this channel have become more subdued, especially among lower-rating and lower maturity bonds, which should be a consequence of the recent financial crisis.

\subsection{Stock market response to monetary policy shocks}

To provide further evidence on the impact of the financial crisis on our results, we estimate the stock market reaction to monetary policy shocks. Specifically, following Bernanke and Kuttner (2005) and Maio (2014), we compute the contemporaneous effect of monetary policy shocks on the excess stock market return and its components: discount rate news (equity premia), cash flows news, and interest rate news. Our VAR state vector includes the term spread, default spread, the one-month Treasury bill rate (as in the benchmark VAR for bond returns presented above) in addition to the excess market return and the dividend yield. ${ }^{29} 30$

\footnotetext{
${ }^{28}$ The magnitude of discount-rate news is an increased function of both the persistence of the VAR state variables and the magnitudes of the respective coefficients in the VAR equation associated with excess bond returns (first row of A) as discussed in Campbell and Vuolteenaho (2004) and Chen and Zhao (2009). The results in Table 6 show that the slopes associated with the lagged Treasury bill rate tend to be lower in the full sample. Moreover, unreported results show the persistence of the term spread is slightly lower in the full sample.

${ }^{29}$ The dividend yield is a key predictor of the equity premium and hence we include it in the VAR in line with the related literature (Campbell and Shiller, 1988; Campbell and Ammer, 1993; Campbell and Vuolteenaho, 2004; Cochrane, 2008; Maio, 2013a, 2014; Campbell et al., 2017).

${ }^{30}$ In line with previous work (Campbell and Vuolteenaho, 2004; Maio, 2013a; Maio, 2014), the log-linearization parameter $\rho$ is set to $0.95^{1 / 12}$.
} 
Untabulated results show that the total stock return response is significantly smaller in the full sample that includes the financial crisis (-6.83 vs. -8.55 in the restricted sample). Moreover, the impact on discount rate news is also significantly smaller, and less precisely estimates, in the full sample (3.35 vs. 5.30 in the restricted sample). Yet, the discount rate channel dominates the cash-flow channel in both the full (cash-flow response of -2.41) and restricted sample (-2.24), in line with the evidence presented in Bernanke and Kuttner (2005).

From these results it follows that over the restricted sample the negative correlation between stock market returns and monetary policy shocks works mainly trough the discount-rate channel. Second, the total return response (as well as the effect on equity premia news) has been significantly attenuated after the financial crisis. This stems from the already mentioned structural change in the Fed policy but also from the significant hike in stock market volatility during the 2007-09 period. Hence, these results are in line with those obtained for corporate bonds, as discussed above, and confirm that these two asset classes are highly correlated. On the other hand, these results also reinforce that the shift in monetary policy had a severe impact on the way that asset markets in general, not only in corporate bond markets, respond to those shocks. Thus, it is quite unlikely that the high volatility in corporate bond markets in recent years is the only force driving our results discussed above.

\section{$5 \quad$ Robustness checks}

We examine the robustness of our key VAR-based empirical findings in a number of ways and find that the results reported in Section 4 are overall not sensitive to these changes. First, we use alternative state vector specifications for the underlying VAR model. Second, we consider higherorder VARs. Third, we use the consol bond formulas to conduct the variance decomposition for returns on long-term corporate bonds. Fourth, we consider an alternative identification scheme for the components of excess bond returns. Fifth, we use lagged FFR shocks as an exogenous variable in the VAR and also employ the methodology suggested by Romer and Romer (2004) to calculate monetary policy shocks. Finally, we account for risk premia in the FFR futures contracts. To save space, we only present results for the pre-crisis period. The results are presented in Appendix B.

\subsection{Alternative state vector specifications}

The state variables in the VAR are chosen on the basis of their predictive power for excess bond returns. The benchmark VAR state vector includes excess bond returns, the default spread, 
the term spread, and the one-month Treasury bill rate. Here, we augment the state vector by additional macro-financial indicators that may help to forecast bond returns. Specifically, the following variables are considered in turn: the log dividend-to-price ratio on the S\&P 500 stock market index, the Chicago Fed Adjusted National Financial Conditions Index (ANFCI), and the Chicago Fed National Activity Index (CFNAI). CFNAI is a proxy of overall economic activity, calculated as the weighted average of 85 monthly indicators of national economic activity. ANFCI isolates the component of financial conditions (in money, debt, and equity markets, in addition to the traditional and "shadow" banking systems) that is uncorrelated with economic conditions. ${ }^{31}$ Generally, the baseline VAR findings are robust to the inclusion of additional macro-financial state variables. The positive effect of monetary policy easing on excess bond returns mainly comes from a corresponding negative effect on the future bond risk premium.

\subsection{Higher-order VAR models}

The main empirical analysis is based on the first-order VAR model. Nevertheless, one may argue that this specification could be too restrictive and not adequate to capture the dynamic structure of the data. Therefore, we also consider higher-order VARs as in other related studies (Campbell and Ammer, 1993; Maio, 2014). The empirical estimations are repeated using VAR(2), VAR(3), and $\operatorname{VAR}(6)$ models. The state vector remains the same as in the benchmark VAR(1) model. The results are similar across different lags structure, hence, we only report the estimates obtained using $\operatorname{VAR}(3)$ in order to preserve space. Overall, the baseline findings regarding the key role played by discount rate news in terms of explaining the response of excess bond returns to monetary policy shifts during the pre-crisis period is not affected by the alternative VAR order.

\subsection{The case of consol bonds}

Some related studies apply the VAR-based decomposition method for long-term bonds assuming infinite maturity, i.e. the empirical analysis is based on consol (perpetual) bonds (Engsted and Tanggaard, 2007; Bredin et al., 2010). One obvious advantage of this approach is that the problem of shrinking bond maturity over time is not relevant when calculating future excess bond returns directly from the estimated VAR. Here, we apply the methodology and formulas as provided in Bredin et al. (2010) on the long-term corporate bonds using the same data as before. In line with our benchmark analysis, we extract interest rate news as a residual

\footnotetext{
${ }^{31}$ The calculation of the market-wide log dividend-to-price ratio is based on data provided by Robert J. Shiller at: http://www.econ.yale.edu/ shiller/data.htm. The ANFCI and CFNAI indices are obtained from the FREDII database.
} 
component using the dynamic identity relationship. The results are nearly identical to those for long-term bonds discussed in the previous section. Hence, our approach of assuming long-term bonds as $n$-maturity bonds does not lead to different findings. This also implies that our results are not driven by the fact that we do not account for shrinking bond maturity over time.

\subsection{Alternative identification scheme for excess returns components}

We examine whether a different identification scheme has implications for our main findings. The interest rate news component is now estimated directly from the first-order VAR while the discount rate news is calculated as the residual term. The baseline findings are non-sensitive to this alternative identification scheme. As in the benchmark case, the contemporaneous reaction of bond returns to monetary policy shocks can be attributed to shifts in expected bond returns over the restricted sample.

\subsection{Revisiting endogeneity}

We address the potentially endogenous nature of our monetary policy indicator in two ways. First, we use the one-period lagged monetary policy shock as an exogenous variable in the VAR to deal with potential simultaneity. Second, we follow the methodology proposed by Romer and Romer (2004) to identify monetary policy shocks that take into account the central bank's response to expected economic conditions. The calculation of Romer and Romers (2004) monetary policy shocks involves two steps. First, intended federal funds rate changes around the FOMC meetings are identified. Second, the intended funds rate changes are regressed on the internal FOMC forecasts for inflation and real economic activity, i.e. the Greenbook forecasts, around the dates of these forecasts; see Equation (1) in Romer and Romer (2004). Residuals from that regression represent monetary policy shocks. The results from these estimations provide insights that are qualitatively similar with the baseline findings concerning the important role of discount rate news in driving policy effects on bond returns.

\subsection{Risk premium-adjusted monetary policy shocks}

We use risk-adjusted futures contracts rates as a measure of monetary policy expectations following Cenesizoglu and Essid (2012). The excess returns on FFR futures contracts are calculated as the difference between the rate implied by the one-month-ahead Fed funds future at the end of the previous month and the average actual effective Fed funds rate in that month. We regress excess returns on a constant and the NBER recession dummy and then deduct the fitted 
value from that regression from the futures contract rate. Next, we use these adjusted series to compute the monetary policy shocks in Equation (1). The results that we obtain using the risk-adjusted monetary policy shocks are similar to the baseline findings.

\section{The role of term and credit risk premia news}

In this section, we compute an alternative bond return decomposition, which disentangles bond premia news into one component related to term premia and another component related with credit premia.

The two-way decomposition that we presented in Equation (5) can be expanded by separating the credit risk premium and term premium component of discount rate news. To do so, we express excess bond returns as follows:

$$
x_{n, t+1}=x_{n, t+1}^{C}+x_{n, t+1}^{G},
$$

where $x_{n, t+1}^{C}$ denotes the return on (a $n$-maturity) corporate bond in excess of the return on a Treasury bond with similar maturity, and $x_{n, t+1}^{G}$ denotes the excess Treasury bond return relative to the short-term risk-free rate. ${ }^{32}$ Using Equation (15), Equation (5) becomes:

$$
\begin{gathered}
\tilde{x}_{n, t+1}=\left(E_{t+1}-E_{t}\right)\left[-\sum_{j=1}^{n-1} \rho^{j} x_{n-j, t+1+j}^{C}-\sum_{j=1}^{n-1} \rho^{j} x_{n-j, t+1+j}^{G}-\sum_{j=1}^{n-1} \rho^{j} y_{t+1+j}\right] \Leftrightarrow \\
\tilde{x}_{n, t+1}=-\tilde{x}_{x, t+1}^{C}-\tilde{x}_{x, t+1}^{G}-\tilde{x}_{y, t+1} .
\end{gathered}
$$

Hence, current period unexpected excess bond returns are decomposed into news about future credit risk premia $\left(\tilde{x}_{x, t+1}^{C}\right)$, news about future term premia $\left(\tilde{x}_{x, t+1}^{G}\right)$, as well as interest rate news. ${ }^{33}$

The variance decomposition results corresponding to the expanded set of news components are shown in Table 9. The key finding is that the role of term premium news is overall more crucial relative to that of news about credit risk premia. For example, during the pre-crisis period it follows that more than $50 \%$ (between $59 \%$ and $71 \%$ ) of the variance of excess return innovations can be attributed to term premium news across all six bond categories. In comparison the shares associated with credit risk premia are below $15 \%$ (between $1 \%$ and 13\%) in all cases, and none of these estimates are statistically significant at the $10 \%$ level. On the other hand, the weights

\footnotetext{
${ }^{32}$ The source of the Treasuries data (five-year and twenty-year Treasury bond indices) is CRSP.

${ }^{33}$ In Appendix C, we provide details on the derivation and the identification of the news terms from VAR estimates.
} 
corresponding to interest rate news are statistically significant in the case of long-maturity bonds, but the magnitudes are substantially smaller than those attached to term premia news. When we consider the full sample period, the estimates for the share of term premia news are smaller and less precisely estimated (especially among intermediate maturity bonds).

Table 10 presents the monetary policy effects by using the alternative bond return decomposition. In line with the benchmark findings of Section 4, the full sample results do not provide significant evidence in support of risk premia as a factor that can explain the response of bond returns to monetary policy shocks: the estimated effects on both credit premia and term premia news are insignificant in most cases, the sole exception being the term premia policy response associated with the long AAA index (significant at the $10 \%$ level).

The pre-crisis estimates, however, indicate that risk premia play a crucial role. Specifically, term premium news constitute the most relevant component across the different maturities and credit ratings: the response estimates vary between 1.65 (intermediate AAA bonds) and 2.79 (long A bonds) and these estimates are significant (1\% level) in all six cases. On the other hand, the shares corresponding to credit premia news have substantially smaller magnitudes and are insignificant for all six bonds. Specifically, the share of term premium news in the total response of intermediate maturity AAA bonds is $72 \%(1.65 / 2.28)$ while that of credit risk premium news is only $11 \%(0.24 / 2.28)$. In the case of intermediate A bonds, the corresponding shares are $59 \%$ and $6 \%$, respectively. The weights associated with interest rate news are similar to the corresponding estimates in the benchmark decomposition (only in the case of the long A bonds are these estimates estimates statistically significant).

Therefore, our findings strongly suggest that the reaction of the higher quality segment (AAA to A ratings) of the corporate bond market to monetary policy shocks over the 1989-2007 period is primarily related to risk premium revisions, which in turn are related with the slope of the yield curve instead of credit risk.

\section{Conclusion}

There is a vast amount of literature on the monetary policy implications for asset prices. Generally, stock and government bond markets have been the focus of the attention while there is significantly less empirical work carried out with respect to corporate bonds. The aim of this paper is to examine whether conventional U.S. monetary policy, measured by FFR shocks, has any implications for corporate bond returns and their components. Our analysis is timely since the Fed is in the process of normalising monetary conditions following a prolonged period of 
ultra-loose monetary policy. Moreover, we shed some light on the impact of the recent financial crisis on the empirical relationship between corporate bond market movements and monetary policy actions. To start, we simply regress monthly excess bond returns on a monetary policy indicator to provide an estimation of the respective contemporaneous correlation. Next, we adapt the log-linear return decomposition framework of Campbell and Ammer (1993) together with a first-order VAR model to decompose the monetary policy effects on unexpected excess bond returns in terms of their two components: discount rate news and interest rate news.

By conducting simple regressions over the 1989.02-2013.12 and 1989.02-2007.07 periods, we obtain a negative and significant response of excess returns on corporate bonds to shocks in FFR prior to the financial crisis. This conclusion remains valid across both medium and longer maturities as well as across different credit ratings. The effect of monetary policy on bond returns is weaker and less significant in the full sample, indicating potential implications of the financial crisis and the subsequent change in the Fed's policy stance. Similar results are obtained when we examine monetary policy effects on unexpected excess bond returns, which are obtained from a first-order VAR.

With respect to the bond return variance decomposition, our results demonstrate that the key determinant of the variability in current unexpected excess returns on long-term and intermediate term corporate bonds is the variation in the revisions in expectations about future bond risk premia. The other component of excess bond returns (interest rate news) plays only a limited role. These results holds across all three credit ratings considered, and are also robust to the 2007-2009 financial crisis. More importantly, for the pre-crisis period we provide evidence that discount rate news constitute the key driving force that explains the response of bond returns to monetary shocks. In other words, the largest share of the contemporaneous negative response of corporate bond returns to monetary policy tightening can be attributed to higher expected excess bond returns (higher bond risk premia). In terms of explaining the negative effect of interest rate rises on current returns, the impact of monetary shocks on expectations of future short-term interest rates is relatively small. Thus, our results suggest that an important channel via which monetary policy affects corporate bonds operates through discount rate news. These results are robust across the six bond indices analyzed, however, some relevant differences across these bond categories exist.

The results for the full sample that includes the recent financial turmoil (2007-2009) are rather different. During this period, across most of the bond indices considered, upward revisions in future short-term interest rates can explain the negative bond return responses to monetary 
tightening shocks. The bond premia channel is significantly less relevant, compared to the interest rate channel, in explaining the impact of Fed policy on bond returns. These results should be a consequence of two facts that originated in the recent financial crisis. First, the significant increase in corporate bond price volatility, and the widening of credit spreads. Second, the change in Fed policy by adopting a ultra-expansionary stance which led the Fed funds target to the zero-lower bound (along with the adoption of unconventional policies, involving new interventions in credit and bond markets). Both events probably lead to significant outliers in the relationship between FFR shocks and corporate bond returns, and the estimation of the bond return decomposition. This could be relevant to explain the significant attenuation of the impact of policy shocks on bond premia news when the most recent period is included in the sample.

In the last part of the paper, we compute an alternative bond return decomposition, which disentangles bond premia news into one component related to term premia news and another component related with credit premia news. Our findings clearly suggest that the reaction of the corporate bond market to monetary policy shifts is primarily related to risk premium revisions that are related with the slope of the yield curve (term premia news) rather than related to credit risk (credit premia news). Hence, term premia plays a more important role in driving expected bond returns, at least in what concerns the reaction to monetary policy surprises. 


\section{References}

Abhyankar, A. and Gonzalez, A., 2009. News and the cross-section of expected corporate bond returns, Journal of Banking and Finance, 33 (6), 996-1004.

Avramov, D., Jostova, G., and Philipov, A., 2007. Understanding changes in corporate credit spreads, Financial Analysts Journal, 63 (2), 90-105.

Baker, M., Greenwood, R., and Wurgler, J., 2003. The maturity of debt issues and predictable variation in bond returns, Journal of Financial Economics, 70 (2), 261-291.

Bali, T.G. and Wen, Q., 2017. Macroeconomomic uncertainty and corporate bond returns, Working paper, Georgetown University.

Barr, D.G. and Pesaran, B., 1997. An assessment of the relative importance of real interest rates, inflation, and term premiums in determining the prices of real and nominal UK bonds, Review of Economics and Statistics, 79 (3), 362-366.

Bernanke, B.S. and Blinder, A.S., 1992. The federal funds rate and the channels of monetary transmission, American Economic Review, 82 (4), 901-921.

Bernanke, B.S. and Gertler, M., 1995. Inside the black box: The credit channel of monetary policy transmission, Journal of Economic Perspectives, 9 (4), 27-48.

Bernanke, B.S. and Kuttner, K.N., 2005. What explains the stock market's reaction to Federal Reserve policy?, Journal of Finance, 60 (3), 1221-1257.

Bernanke, B.S. and Mihov, I., 1998. Measuring monetary policy, Quarterly Journal of Economics, 113 (3), 869-902.

Bessembinder, H., Kahle, K.M., Maxwell, W.F., and Xu, D., 2009. Measuring abnormal bond performance, Review of Financial Studies, 22 (10), 4219-4258.

Boivin, J., Kiley, M.T., and Mishkin, F.S., 2010. How has the monetary transmission mechanism evolved over time?, Working Paper 15879, National Bureau of Economic Research.

Bredin, D., Hyde, S., and Reilly, G.O., 2010. Monetary policy surprises and international bond markets, Journal of International Money and Finance, 29 (6), 988-1002.

Brennan, M.J., Wang, A.W., and Xia, Y., 2004. Estimation and test of a simple model of intertemporal capital asset pricing, Journal of Finance, 59 (4), 1743-1775. 
Brunnermeier, M.K., 2009. Deciphering the liquidity and credit crunch 2007-2008, Journal of Economic Perspectives, 23 (1), 77-100.

Campbell, J.Y., 1991. A variance decomposition for stock returns, Economic Journal, 101 (405), $157-179$.

Campbell, J.Y. and Ammer, J., 1993. What moves the stock and bond markets? A variance decomposition for long-term asset returns, Journal of Finance, 48 (1), 3-37.

Campbell, J.Y., Giglio, S., Polk, C., and Turley, R., 2017. An intertemporal CAPM with stochastic volatility, Journal of Financial Economics, Forthcoming.

Campbell, J.Y., Lo, A.W.C., and MacKinlay, A.C., 1997. The econometrics of financial markets, Princeton University Press Princeton, NJ.

Campbell, J.Y. and Shiller, R.J., 1988. The dividend-price ratio and expectations of future dividends and discount factors, Review of Financial Studies, 1 (3), 195-228.

Campbell, J.Y. and Vuolteenaho, T., 2004. Bad beta, good beta, American Economic Review, 94 (5), 1249-1275.

Cenesizoglu, T. and Essid, B., 2012. The effect of monetary policy on credit spreads, Journal of Financial Research, 35 (4), 581-613.

Chen, L. and Zhao, X., 2009. Return decomposition, Review of Financial Studies, 22, 5213-5246.

Christensen, J.H. and Rudebusch, G.D., 2012. The response of interest rates to US and UK quantitative easing, Economic Journal, 122 (564), 385-414.

Chun, O.M., Dionne, G., and Francois, P., 2014. Detecting regime shifts in credit spreads, Journal of Financial and Quantitative Analysis, 49 (5-6), 1339-1364.

Cochrane, J.H., 2008. The dog that did not bark: A defense of return predictability, Review of Financial Studies, 21 (4), 1533-1575.

Cochrane, J.H. and Piazzesi, M., 2002. The Fed and interest rates-A high-frequency identification, American Economic Review, 92 (2), 90-95.

Collin-Dufresne, P., Goldstein, R.S., and Martin, J.S., 2001. The determinants of credit spread changes, Journal of Finance, 56 (6), 2177-2207. 
Curdia, V. and Woodford, M., 2010. Credit spreads and monetary policy, Journal of Money, Credit and Banking, 42 (6), 3-35.

Driessen, J., 2005. Is default event risk priced in corporate bonds?, Review of Financial Studies, $18(1), 165-195$.

Elton, E.J., Gruber, M.J., Agrawal, D., and Mann, C., 2001. Explaining the rate spread on corporate bonds, Journal of Finance, 56 (1), 247-277.

Elton, E.J., Gruber, M.J., and Blake, C.R., 1995. Fundamental economic variables, expected returns, and bond fund performance, The Journal of Finance, 50 (4), 1229-1256.

Engsted, T., Pedersen, T.Q., and Tanggaard, C., 2012. Pitfalls in VAR based return decompositions: A clarification, Journal of Banking and Finance, 36 (5), 1255-1265.

Engsted, T. and Tanggaard, C., 2001. The Danish stock and bond markets: Comovement, return predictability and variance decomposition, Journal of Empirical Finance, 8 (3), 243-271.

Engsted, T. and Tanggaard, C., 2007. The comovement of US and German bond markets, International Review of Financial Analysis, 16 (2), 172-182.

Evans, C. and Kuttner, K.N., 1998. Can VARs describe monetary policy?, Working Paper Series 98-19, Federal Reserve Bank of Chicago.

Fama, E.F., 2013. Does the Fed control interest rates?, Review of Asset Pricing Studies, 3 (2), 180-199.

Fama, E.F. and French, K.R., 1989. Business conditions and expected returns on stocks and bonds, Journal of Financial Economics, 25 (1), 23-49.

Fama, E.F. and French, K.R., 1993. Common risk factors in the returns on stocks and bonds, Journal of Financial Economics, 33 (1), 3-56.

Gagnon, J., Raskin, M., Remache, J., and Sack, B., 2011. Large-scale asset purchases by the federal reserve: Did they work?, Federal Reserve Bank of New York Economic Policy Review, $17(1), 41-59$.

Gebhardt, W.R., Hvidkjaer, S., and Swaminathan, B., 2005. The cross-section of expected corporate bond returns: Betas or characteristics?, Journal of Financial Economics, 75 (1), $85-114$. 
Gertler, M. and Karadi, P., 2015. Monetary policy surprises, credit costs, and economic activity, American Economic Journal: Macroeconomics, 7 (1), 44-76.

Giesecke, K., Longstaff, F.A., Schaefer, S., and Strebulaev, I., 2011. Corporate bond default risk: A 150-year perspective, Journal of Financial Economics, 102 (2), 233 - 250.

Gilchrist, S. and Zakrajsek, E., 2012. Credit spreads and business cycle fluctuations, American Economic Review, 102 (4), 1692-1720.

Goltz, F. and Campani, C.H., 2011. A review of corporate bond indices: Construction principles, return heterogeneity, and fluctuations in risk exposures, Working paper, EDHEC - Risk Institure.

Goyal, A. and Santa-Clara, P., 2003. Idiosyncratic risk matters!, Journal of Finance, 58 (3), 975-1007.

Greenwood, R. and Hanson, S.G., 2013. Issuer quality and corporate bond returns, Review of Financial Studies, 26 (6), 1483-1525.

Gurkaynak, R.S., Sack, B., and Swansonc, E.T., 2005. Do actions speak louder than words? The response of asset prices to monetary policy actions and statements, International Journal of Central Banking, 1 (1), 55-93.

Hanson, S.G. and Stein, J.C., 2015. Monetary policy and long-term real rates, Journal of Financial Economics, 115 (3), 429-448.

Javadi, S., Nejadmalayeri, A., and Krehbiel, T.L., 2017. Do FOMC actions speak loudly? Evidence from corporate bond credit spreads, Review of Finance, Forthcoming.

Jensen, G.R., Mercer, J.M., and Johnson, R.R., 1996. Business conditions, monetary policy, and expected security returns, Journal of Financial Economics, 40 (2), 213-237.

Keim, D.B. and Stambaugh, R.F., 1986. Predicting returns in the stock and bond markets, Journal of Financial Economics, 17 (2), 357-390.

Kontonikas, A. and Kostakis, A., 2013. On monetary policy and stock market anomalies, Journal of Business Finance and Accounting, 40 (7-8), 1009-1042.

Kontonikas, A., MacDonald, R., and Saggu, A., 2013. Stock market reaction to Fed funds rate surprises: State dependence and the financial crisis, Journal of Banking and Finance, 37 (11), 4025-4037. 
Kontonikas, A., Nolan, C., and Zekaite, Z., 2015. Always and everywhere inflation? Treasuries variance decomposition and the impact of monetary policy, Discussion Paper Series 2015-17, University of Glasow.

Krishnamurthy, A. and Vissing-Jorgensen, A., 2011. The effects of Quantitative Easing on interest rates: Channels and implications for policy, Brookings Papers on Economic Activity, 2, $215-287$.

Kuttner, K.N., 2001. Monetary policy surprises and interest rates: Evidence from the Fed funds futures market, Journal of Monetary Economics, 47 (3), 523-544.

Lin, H., Wu, C., and Zhou, G., 2017. Forecasting corporate bond returns with a large set of predictors: An iterated combination approach, Management Science, Forthcoming.

Lioui, A. and Maio, P., 2014. Interest rate risk and the cross section of stock returns, Journal of Financial and Quantitative Analysis, 49 (02), 483-511.

Maio, P., 2013a. Intertemporal CAPM with conditioning variables, Management Science, 59 (1), $122-141$.

Maio, P., 2013b. The Fed model and the predictability of stock returns, Review of Finance, $17(4), 1489-1533$.

Maio, P., 2014. Another look at the stock return response to monetary policy actions, Review of Finance, 18, 321-371.

Maio, P. and Philip, D., 2015. Macro variables and the components of stock returns, Journal of Empirical Finance, 33 (287-308).

Maio, P. and Santa-Clara, P., 2012. Multifactor models and their consistency with the icapm, Journal of Financial Economics, 106 (3), 586 - 613.

Maio, P. and Santa-Clara, P., 2017. Short-term interest rates and stock marketanomalies, Journal of Financial and Quantitative Analysis, 52 (3), 927-961.

Nozawa, Y., 2017. What drives the cross-section of credit spreads?: A variance decomposition approach, Journal of Finance, 72 (5), 2045-2072.

Petkova, R., 2006. Do the Fama-French factors proxy for innovations in predictive variables?, Journal of Finance, 61 (2), 581-612. 
Piazzesi, M. and Swanson, E.T., 2008. Futures prices as risk-adjusted forecasts of monetary policy, Journal of Monetary Economics, 55 (4), 677-691.

Romer, C.D. and Romer, D.H., 2004. A new measure of monetary shocks: Derivation and implications, American Economic Review, 94 (4), 1055-1084.

Sangvinatsos, A., 2005. Explanatory and predictive analysis of corporate bond indices returns, Working paper, New York University, Department of Finance.

Standard\&Poors, 2015. Default, transition, and recovery: 2014 annual global corporate default study and rating transitions, Tech. rep., Standard \& Poors.

Taylor, J.B., 2008. Monetary policy and the state of the economy, Testimony before the Committee on Financial Services, US House of Representatives.

Thorbecke, W., 1997. On stock market returns and monetary policy, Journal of Finance, 52 (2), 635-654.

Vuolteenaho, T., 2002. What drives firm-level stock returns?, Journal of Finance, 57 (1), 233264.

Welch, I. and Goyal, A., 2008. A comprehensive look at the empirical performance of equity premium prediction, Review of Financial Studies, 21 (4), 1455-1508.

White, H., 1980. A heteroskedasticity-consistent covariance matrix estimator and a direct test for heteroskedasticity, Econometrica, 48 (4), 817-838.

Wright, J.H., 2012. What does monetary policy do to long-term interest rates at the zero lower bound?, Economic Journal, 122 (564), 447-466. 


\section{A Bond return decomposition and VAR identification}

This appendix provides a summary of the key steps for the decomposition of unexpected excess bond returns in terms of news components and the VAR-based empirical identification. The starting point is the definition of bond returns. The gross nominal holding-period return $\left(1+R_{n, t+1}\right)$ on an $n$-period coupon bond, or equivalently a bond index with $n$-period average maturity, from $t$ to $t+1$ is

$$
1+R_{n, t+1}=\frac{P_{n-1, t+1}+C}{P_{n, t}}
$$

where $P_{n, t}$ denotes the bond price at period $t$ and $C$ is the respective coupon. By taking $\operatorname{logs}$ on both sides of Equation (A1), we obtain the log nominal holding-period return:

$$
r_{n, t+1}=p_{n-1, t+1}-p_{n, t}+\ln \left(1+e^{c-p_{n-1, t+1}}\right)
$$

where $p=\ln (P)$ and $c=\ln (C)$ denote the log price and log coupon, respectively. The non-linear term, $\ln \left(1+e^{c-p_{n-1, t+1}}\right)$, can be approximated around the mean of the log coupon-price ratio, $\overline{c-p}$, by using a first-order Taylor expansion. Consequently, we have:

$$
r_{n, t+1} \approx k+\rho p_{n-1, t+1}+(1-\rho) c-p_{n, t},
$$

where $k=-\ln (\rho)-(1-\rho) \ln \left(\frac{1}{\rho}-1\right)$ and $\rho=\frac{1}{1+e^{\overline{c-p}}} \approx \frac{1}{1+\overline{Y_{n}}} \cdot \overline{Y_{n}}$ is the average yield to maturity of the bond. This definition of $\rho$ gives a good approximation for returns on bonds selling close to par (Campbell et al., 1997).

By re-arranging Equation (A3), solving forward, and taking expectations at time $t$, we can express the log price in terms of expected future returns and coupon payments:

$$
\left.p_{n, t}=E_{t} \sum_{j=0}^{n-1} \rho^{j}\left[k+(1-\rho) c-r_{n-j, t+1+j}\right)\right] .
$$

By using (A4) and (A3), we obtain an expression for current unexpected bond returns, in which this variable is negatively related to revisions in expectations of future bond returns:

$$
r_{n, t+1}-E_{t}\left[r_{n, t+1}\right]=-\left(E_{t+1}-E_{t}\right)\left[\sum_{j=1}^{n-1} \rho^{j} x_{n-j, t+1+j}\right] .
$$


On the other hand, excess bond returns are defined as follows:

$$
x_{n, t+1}=r_{n, t+1}-y_{t+1}
$$

where $y_{t+1}$ is the log nominal short-term risk-free rate.

We can then re-write Equation (A6) in terms of excess returns and obtain the following equation, which decomposes unexpected excess bond returns $\left(\tilde{x}_{n, t+1}\right)$ into discount rate news $\left(\tilde{x}_{x, t+1}\right)$ and interest rate news $\left(\tilde{x}_{y, t+1}\right)$ :

$$
\begin{array}{r}
\tilde{x}_{n, t+1}=x_{n, t+1}-E_{t}\left[x_{n, t+1}\right]=\left(E_{t+1}-E_{t}\right)\left[-\sum_{j=1}^{n-1} \rho^{j} x_{n-j, t+1+j}-\sum_{j=1}^{n-1} \rho^{j} y_{t+1+j}\right] \\
=-\tilde{x}_{x, t+1}-\tilde{x}_{y, t+1},
\end{array}
$$

where $\tilde{x}_{x, t+1}=\left(E_{t+1}-E_{t}\right) \sum_{j=1}^{n-1} \rho^{j} x_{n-j, t+1+j}$, and $\tilde{x}_{y, t+1}=\left(E_{t+1}-E_{t}\right) \sum_{j=1}^{n-1} \rho^{j} y_{t+1+j}$.

In order to obtain empirical proxies for unexpected excess bond returns and their (newsrelated) components, we employ the VAR approach widely used in the literature (Campbell, 1991). Consider a first-order VAR model:

$$
\mathbf{z}_{t+1}=\boldsymbol{\theta}+\mathbf{A} \mathbf{z}_{t}+\mathbf{w}_{t+1}
$$

where the VAR state vector is given by $\mathbf{z}_{t+1}=\left[x_{n, t+1}, d e f_{t+1}, t e r m_{t+1}, y_{t+1}\right]^{\prime} \cdot x_{n}$ denotes excess bond returns; def denotes the default spread; term is the term spread; and $y$ is the continuously compounded one-month Treasury bill rate. $\boldsymbol{\theta}$ is a vector of intercept terms, $\mathbf{A}$ denotes a matrix of VAR parameters, and $\mathbf{w}_{t+1}$ is a vector of forecasting residuals.

The unexpected one-period excess bond return at time $t+1\left(\tilde{x}_{n, t+1}\right)$ is directly obtainable from the first equation of the VAR system:

$$
\tilde{x}_{n, t+1}=x_{n, t+1}-E_{t}\left[x_{n, t+1}\right]=\mathbf{s}_{1}^{\prime} \mathbf{w}_{t+1},
$$

where $\mathbf{s}_{i}^{\prime}$ is a unit selection vector with $i$ representing the $i^{\text {th }}$ equation in the VAR model, and accordingly the $i^{\text {th }}$ element of the vector is set to 1 . Hence, $\mathbf{s}_{1}^{\prime}=[1,0,0,0]$ selects the residuals of the first equation in the VAR (excess bond return equation) as a proxy for the unexpected excess bond return.

Projections from the error vector are used to empirically approximate revisions in expecta- 
tions about future excess returns:

$$
\left(E_{t+1}-E_{t}\right) \mathbf{z}_{t+1+j}=\mathbf{A}^{j} \mathbf{w}_{t+1} .
$$

It can then be shown that discount rate news can be expressed in terms of the VAR estimates:

$$
\tilde{x}_{x, t+1}=\left(E_{t+1}-E_{t}\right) \sum_{j=1}^{n-1} \rho^{j} x_{n-j, t+1+j}=\mathbf{s}_{1}^{\prime} \sum_{j=1}^{n-1} \rho^{j} \mathbf{A}^{j}\left(\mathbf{z}_{t+1}-\boldsymbol{\theta}-\mathbf{A} \mathbf{z}_{t}\right)=\mathbf{s}_{1}^{\prime} \sum_{j=1}^{n-1}(\rho \mathbf{A})^{j} \mathbf{w}_{t+1} .
$$

By using the geometric series properties, we obtain the following expression for discount rate news:

$$
\tilde{x}_{x, t+1}=\mathbf{s}_{1}^{\prime}(\mathbf{I}-\rho \mathbf{A})^{-1}\left(\rho \mathbf{A}-\rho^{n} \mathbf{A}^{n}\right) \mathbf{w}_{t+1},
$$

where $\mathbf{I}$ is the identity matrix.

Finally, we obtain interest rate news as the residual component from the dynamic identity in Equation (A7):

$$
\tilde{x}_{y, t+1}=-\tilde{x}_{n, t+1}-\tilde{x}_{x, t+1} .
$$

\section{B Additional results}

This appendix describes the tables that contain the results of the robustness section (Section $5)$ in the paper. Tables A.1-A.3 report the monetary policy impact on the unexpected excess bond returns and its respective components employing alternative state vectors. Table A.4 presents results based upon a higher order, $\operatorname{VAR}(3)$, model. The responses associated with a dynamic decomposition for consol bonds are presented in Table A.5. Table A.6 reports the results for an alternative identification of excess bond returns. Tables A.7 and A.8 report monetary policy impact estimates using one-period lagged monetary policy shocks and the shocks that are calculated using the methodology proposed by Romer and Romer (2004), respectively. The results from risk-premium adjusted monetary policy shocks are shown in Table A.9.

\section{Alternative bond return decomposition}

We decompose the excess corporate bond return into two components,

$$
x_{n, t+1}=x_{n, t+1}^{C}+x_{n, t+1}^{G},
$$


where $x_{n, t+1}^{C}$ denotes the return on (a $n$-maturity) corporate bond in excess of the return on a Treasury bond with similar maturity, and $x_{n, t+1}^{G}$ denotes the excess Treasury bond return relative to the short-term risk-free rate. By substituting this definition into the decomposition for the innovation in the current excess corporate bond return, we obtain,

$$
\begin{gathered}
\tilde{x}_{n, t+1}=\left(E_{t+1}-E_{t}\right)\left[-\sum_{j=1}^{n-1} \rho^{j} x_{n-j, t+1+j}^{C}-\sum_{j=1}^{n-1} \rho^{j} x_{n-j, t+1+j}^{G}-\sum_{j=1}^{n-1} \rho^{j} y_{t+1+j}\right] \Leftrightarrow \\
\tilde{x}_{n, t+1}=-\tilde{x}_{x, t+1}^{C}-\tilde{x}_{x, t+1}^{G}-\tilde{x}_{y, t+1} .
\end{gathered}
$$

Under this new decomposition, discount rate news $\left(\tilde{x}_{x, t+1}\right)$ are decomposed in a component that reflects only news about future credit risk premia $\left(\tilde{x}_{x, t+1}^{C}\right)$ and another component that reflects entirely news about future term risk premia $\left(\tilde{x}_{x, t+1}^{G}\right)$.

To identify the components of the return decomposition presented above, we estimate a first-order VAR where the state vector is given by

$$
\mathbf{z}_{t+1}=\left[x_{n, t+1}, x_{n, t+1}^{G}, \operatorname{def}_{t+1}, \operatorname{term}_{t+1}, y_{t+1}\right]^{\prime},
$$

where the variables, other than $x_{n, t+1}^{G}$, are the same as before.

The three news components are identified as follows:

$$
\begin{gathered}
\tilde{x}_{n, t+1} \equiv x_{n, t+1}-E_{t}\left[x_{n, t+1}\right]=\mathbf{s}_{1}^{\prime} \mathbf{w}_{t+1}, \\
\tilde{x}_{x, t+1}^{C} \equiv\left(E_{t+1}-E_{t}\right) \sum_{j=1}^{n-1} \rho^{j} x_{n-j, t+1+j}^{C}=\left(\mathbf{s}_{1}-\mathbf{s}_{2}\right)^{\prime}(\mathbf{I}-\rho \mathbf{A})^{-1}\left(\rho \mathbf{A}-\rho^{n} \mathbf{A}^{n}\right) \mathbf{w}_{t+1}, \\
\tilde{x}_{x, t+1}^{G} \equiv\left(E_{t+1}-E_{t}\right) \sum_{j=1}^{n-1} \rho^{j} x_{n-j, t+1+j}^{G}=\mathbf{s}_{2}^{\prime}(\mathbf{I}-\rho \mathbf{A})^{-1}\left(\rho \mathbf{A}-\rho^{n} \mathbf{A}^{n}\right) \mathbf{w}_{t+1},
\end{gathered}
$$

and

$$
\tilde{x}_{y, t+1} \equiv\left(E_{t+1}-E_{t}\right) \sum_{j=1}^{n-1} \rho^{j} y_{t+1+j}=-\tilde{x}_{n, t+1}-\tilde{x}_{x, t+1}^{C}-\tilde{x}_{x, t+1}^{G} .
$$


Figure 1: Barclays corporate bond indices

This figure plots the monthly time-series for the following Barclays corporate bond indices: longterm $(L)$ maturity with A and AAA ratings; intermediate $(I)$ maturity with A and AAA ratings. Shaded areas denote US recessions as classified by NBER business cycle dates. The series have been normalised so that they are equal to 100 at the start of the sample period. The sample period is 1989.02-2013.12.

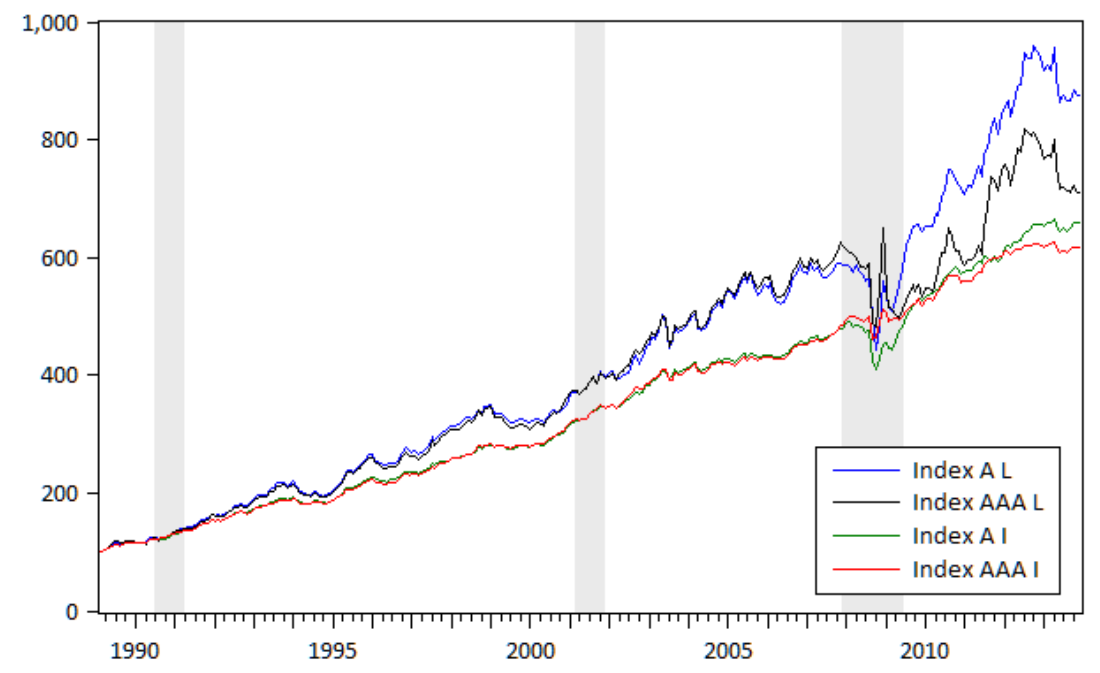


Figure 2: Monetary policy shocks

This figure plots the monthly time-series for monetary policy shocks $(M P)$, proxied by the unexpected change in the FFR. See Section 2 for more details. Shaded areas denote US recessions as classified by NBER business cycle dates. The sample period is 1989.02-2013.12.

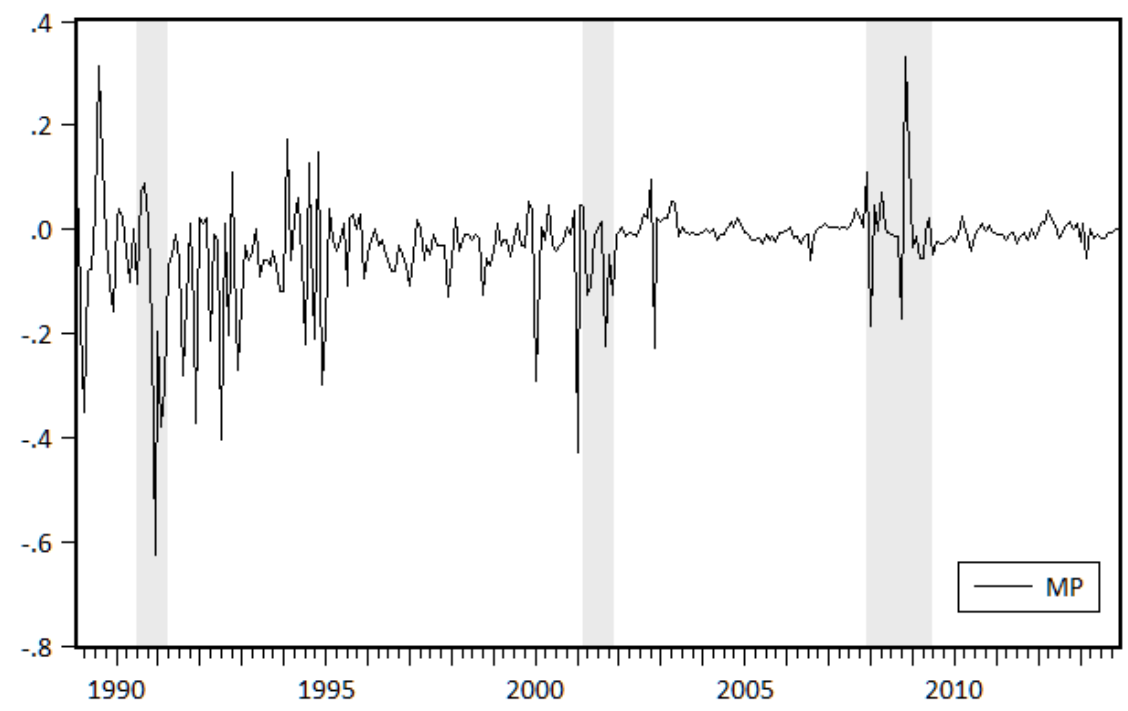


Table 1: Descriptive statistics for monetary policy shocks and VAR state variables

This table presents descriptive statistics for the monetary policy shocks proxy (unexpected change in the FFR; $M P$ ) and the state variables used in the VAR analysis of Section 4. The state variables are the excess returns on Barclays corporate bond indices; the default spread (def); the term spread (term); and the continuously compounded one-month Treasury bill rate $(y)$. The Barclays indices represent portfolios of long-term $(L)$ and intermediate $(I)$ maturity corporate bonds with AAA, AA, and A ratings. The full sample period is 1989.02-2013.12 and the pre-crisis period is 1989.02-2007.07.

\begin{tabular}{cccccccccc}
\hline \hline & Mean & Stdev. & Min. & Max. & Mean & Stdev. & Min. & Max. \\
\hline \multicolumn{7}{c}{ Panel A: Full sample } \\
\hline$A A A^{L}$ & 0.37 & 3.10 & -19.26 & 16.78 & def & 2.25 & 0.78 & 1.25 & 5.92 \\
$A A^{L}$ & 0.47 & 2.74 & -9.90 & 16.44 & term & 1.76 & 1.27 & -1.34 & 4.08 \\
$A^{L}$ & 0.44 & 2.78 & -12.76 & 15.65 & $y$ & 0.28 & 0.20 & 0.00 & 0.79 \\
$A A A^{I}$ & 0.33 & 1.30 & -7.92 & 5.06 & $M P$ & -0.03 & 0.09 & -0.63 & 0.33 \\
$A A^{I}$ & 0.34 & 1.28 & -6.80 & 5.56 & & & & & \\
$A^{I}$ & 0.35 & 1.46 & -11.62 & 5.46 & & & & & \\
\hline \multicolumn{7}{c}{ Panel B: Pre-crisis } & & & \\
\hline$A A^{L}$ & 0.43 & 2.28 & -9.89 & 6.27 & def & 1.96 & 0.51 & 1.25 & 3.71 \\
$A A^{L}$ & 0.43 & 2.32 & -9.90 & 6.22 & term & 1.56 & 1.33 & -1.34 & 4.08 \\
$A^{L}$ & 0.42 & 2.35 & -9.79 & 6.51 & $y$ & 0.36 & 0.16 & 0.06 & 0.79 \\
$A A A^{I}$ & 0.33 & 1.21 & -4.63 & 3.42 & $M P$ & -0.04 & 0.10 & -0.63 & 0.31 \\
$A A^{I}$ & 0.34 & 1.22 & -3.77 & 3.76 & & & & & \\
$A^{I}$ & 0.33 & 1.22 & -3.29 & 3.77 & & & & & \\
\hline \hline
\end{tabular}


Table 2: Correlation matrix of excess corporate bond returns

This table presents the correlation coefficients for excess returns on Barclays corporate bond indices. The Barclays indices represent portfolios of long-term $(L)$ and intermediate $(I)$ maturity corporate bonds with AAA, AA, and A ratings. The full sample period is 1989.02-2013.12 and the pre-crisis period is $1989.02-2007.07$.

\begin{tabular}{|c|c|c|c|c|c|c|}
\hline & $\overline{A A A^{L}}$ & $\overline{A A A^{L}}$ & $\bar{A}^{L}$ & $\overline{A A A^{1}}$ & $A A^{I}$ & $A^{I}$ \\
\hline \multicolumn{7}{|c|}{ Panel A: Full sample } \\
\hline$A A A^{L}$ & 1.00 & & & & & \\
\hline$A A^{L}$ & 0.92 & 1.00 & & & & \\
\hline$A^{L}$ & 0.88 & 0.97 & 1.00 & & & \\
\hline$A A A^{I}$ & 0.86 & 0.83 & 0.82 & 1.00 & & \\
\hline$A A^{I}$ & 0.79 & 0.86 & 0.87 & 0.94 & 1.00 & \\
\hline$A^{I}$ & 0.76 & 0.83 & 0.88 & 0.90 & 0.96 & 1.00 \\
\hline \multicolumn{7}{|c|}{ Panel B: Pre-crisis } \\
\hline$A A A^{L}$ & 1.00 & & & & & \\
\hline$A A^{L}$ & 0.99 & 1.00 & & & & \\
\hline$A^{L}$ & 0.97 & 0.99 & 1.00 & & & \\
\hline$A A A^{I}$ & 0.92 & 0.91 & 0.89 & 1.00 & & \\
\hline$A A^{I}$ & 0.91 & 0.91 & 0.89 & 0.99 & 1.00 & \\
\hline$A^{I}$ & 0.92 & 0.92 & 0.92 & 0.97 & 0.98 & 1.00 \\
\hline
\end{tabular}


Table 3: Monetary policy shocks and economic news

This table presents the estimated response of monetary policy shocks (unexpected change in the FFR, $M P$ ) to economic news. The latter are calculated on the basis of Reuters Economic Polls as the difference between "actual" (the actual value that was reported by the primary source) minus "median forecast" (the forecast figure from the polls prior to the announcement) after the actual value is released. The following macroeconomic variables are considered: CPI inflation, core CPI inflation, change in nonfarm payrolls, growth rate of industrial production, and growth rate of retail sales (excluding automobiles). The full sample period is 1991.10-2013.12 and the pre-crisis period is 1991.10-2007.07. $\bar{R}^{2}$ is the adjusted $R^{2}$. Heteroskedasticity-consistent standard errors are reported in parentheses. *,**, and ${ }^{* * *}$ denote statistical significance at the $10 \%, 5 \%$, and $1 \%$ levels, respectively.

\begin{tabular}{ccc}
\hline \hline & Panel A: Full sample & Panel B: Pre-crisis \\
\hline CPI inflation & -0.05 & -0.06 \\
& $(0.05)$ & $(0.05)$ \\
Core CPI inflation & 0.04 & 0.09 \\
& $(0.05)$ & $(0.07)$ \\
Nonfarm payrolls & 0.00 & -0.01 \\
& $(0.01)$ & $(0.01)$ \\
Industrial production & $-0.02^{*}$ & -0.01 \\
& $(0.01)$ & $(0.02)$ \\
Retail sales excl. autos & 0.01 & 0.02 \\
& $(0.01)$ & $(0.02)$ \\
$\bar{R}^{2}$ & 0.002 & 0.000 \\
\hline \hline
\end{tabular}


Table 4: Responses of excess bond returns to monetary policy shocks

This table presents the estimated response of excess bond returns to monetary policy shocks (unexpected change in the FFR, $M P$ ), as described in Section 3. Bond returns are calculated using the Barclays corporate bond indices, which represent portfolios of long-term $(L)$ and intermediate $(I)$ maturity corporate bonds with AAA, AA, and A ratings. The full sample period is 1989.02-2013.12 and the pre-crisis period is 1989.02-2007.07. $\bar{R}^{2}$ is the adjusted $R^{2}$. Heteroskedasticity-consistent standard errors are reported in parentheses. ${ }^{*},{ }^{* *}$, and ${ }^{* * *}$ denote statistical significance at the $10 \%, 5 \%$, and $1 \%$ levels, respectively.

\begin{tabular}{ccccccc}
\hline \hline & $A A A^{L}$ & $A A^{L}$ & $A^{L}$ & $A A A^{I}$ & $A A^{I}$ & $A^{I}$ \\
\hline \multicolumn{7}{c}{ Panel A: Full sample } \\
\hline Intercept & 0.32 & $0.42^{* *}$ & $0.37^{* *}$ & $0.27^{* * *}$ & $0.27^{* * *}$ & $0.28^{* * *}$ \\
& $(0.22)$ & $(0.19)$ & $(0.19)$ & $(0.09)$ & $(0.08)$ & $(0.10)$ \\
$M P$ & -1.61 & -1.69 & -2.38 & $-1.94^{*}$ & $-2.24^{* *}$ & $-2.18^{* *}$ \\
& $(2.43)$ & $(2.16)$ & $(2.05)$ & $(1.01)$ & $(0.93)$ & $(0.98)$ \\
$\bar{R}^{2}$ & 0.000 & 0.000 & 0.003 & 0.016 & 0.023 & 0.016 \\
\hline \multicolumn{7}{c}{ Panel B: Pre-crisis } \\
\hline Intercept & 0.23 & 0.22 & 0.18 & $0.20^{* *}$ & $0.20^{* *}$ & $0.19^{* *}$ \\
$M P$ & $(0.16)$ & $(0.17)$ & $(0.17)$ & $(0.09)$ & $(0.09)$ & $(0.09)$ \\
& $-4.90^{* * *}$ & $-5.00^{* * *}$ & $-5.77^{* * *}$ & $-3.00^{* * *}$ & $-3.27^{* * *}$ & $-3.51^{* * *}$ \\
$\bar{R}^{2}$ & $(1.18)$ & $(1.26)$ & $(1.27)$ & $(0.66)$ & $(0.77)$ & $(0.71)$ \\
\hline \hline
\end{tabular}


Table 5: Responses of excess bond returns to monetary policy shocks: controlling for business conditions

This table presents the estimated response of excess bond returns to monetary policy shocks (unexpected change in the FFR, $M P$ ) controlling for business conditions, as described in Section 3. Bond returns are calculated using the Barclays corporate bond indices, which represent portfolios of long-term $(L)$ and intermediate $(I)$ maturity corporate bonds with AAA, AA, and A ratings. The business conditions controls include the default spread (def); the term spread (term); and the log nominal short-term risk free rate $(y)$. The full sample period is 1989.02-2013.12 and the pre-crisis period is 1989.02-2007.07. $\bar{R}^{2}$ is the adjusted $R^{2}$. Heteroskedasticity-consistent standard errors are reported in parentheses. ${ }^{*}, * *$, and ${ }^{* * *}$ denote statistical significance at the $10 \%, 5 \%$, and $1 \%$ levels, respectively.

\begin{tabular}{ccccccc}
\hline \hline & $A A A^{L}$ & $A A^{L}$ & $A^{L}$ & $A A A^{I}$ & $A A^{I}$ & $A^{I}$ \\
\hline \multirow{7}{c}{ Panel A: Full sample } & & & \\
\hline Intercept & 0.49 & -0.55 & 0.52 & -0.39 & -0.45 & -0.08 \\
& $(2.53)$ & $(2.03)$ & $(2.15)$ & $(0.80)$ & $(0.74)$ & $(0.96)$ \\
MP & -2.06 & -2.35 & -3.13 & $-2.19^{* * *}$ & $-2.53^{* * *}$ & $-2.59^{* * *}$ \\
& $(2.45)$ & $(2.04)$ & $(2.04)$ & $(0.96)$ & $(0.91)$ & $(0.95)$ \\
def & -0.18 & 0.54 & 0.22 & 0.33 & 0.35 & 0.25 \\
& $(0.81)$ & $(0.63)$ & $(0.67)$ & $(0.25)$ & $(0.24)$ & $(0.31)$ \\
term & -0.24 & -0.15 & -0.21 & -0.11 & -0.09 & -0.09 \\
& $(0.19)$ & $(0.18)$ & $(0.18)$ & $(0.08)$ & $(0.08)$ & $(0.09)$ \\
$y$ & -0.54 & 0.03 & -1.08 & 0.35 & 0.32 & -0.21 \\
& $(2.35)$ & $(1.94)$ & $(1.98)$ & $(0.79)$ & $(0.73)$ & $(0.90)$ \\
$\bar{R}^{2}$ & 0.000 & 0.012 & 0.004 & 0.041 & 0.051 & 0.027 \\
\hline \multirow{5}{*}{ Intercept } & -0.08 & -0.38 & 0.18 & -0.81 & -1.00 & -0.68 \\
& $(1.19)$ & $(1.24)$ & $(1.23)$ & $(0.55)$ & $(0.54)$ & $(0.57)$ \\
MP & $-5.26^{* * *}$ & $-5.33^{* * *}$ & $-6.19^{* * *}$ & $-3.02^{* * *}$ & $-3.27^{* * *}$ & $-3.58^{* * *}$ \\
& $(1.29)$ & $(1.34)$ & $(1.32)$ & $(0.76)$ & $(0.87)$ & $(0.78)$ \\
def & 0.51 & $0.61^{*}$ & 0.40 & $0.54^{* * *}$ & $0.61^{* * *}$ & $0.50^{* * *}$ \\
& $(0.35)$ & $(0.37)$ & $(0.38)$ & $(0.17)$ & $(0.17)$ & $(0.18)$ \\
term & $-0.25^{*}$ & -0.24 & -0.25 & -0.12 & -0.10 & -0.11 \\
& $(0.15)$ & $(0.15)$ & $(0.15)$ & $(0.08)$ & $(0.08)$ & $(0.08)$ \\
$y$ & -0.86 & -0.68 & -1.18 & 0.38 & 0.49 & 0.13 \\
& $(1.48)$ & $(1.51)$ & $(1.49)$ & $(0.71)$ & $(0.71)$ & $(0.73)$ \\
$\bar{R}^{2}$ & 0.058 & 0.060 & 0.066 & 0.105 & 0.124 & 0.120 \\
\hline \hline
\end{tabular}


Table 6: Excess bond returns forecasting regression in the benchmark VAR

This table presents the estimated coefficients for the excess bond returns equation in the benchmark $\operatorname{VAR}(1)$ model presented in Section 4 . The VAR state vector is given by $\left[x_{n, t+1}, d e f_{t+1}, t e r m_{t+1}, y_{t+1}\right]^{\prime}$, where $x_{n}$ denotes excess returns on the Barclays corporate bond index with average maturity $n$; def denotes the default spread; term is the term spread; and $y$ denotes the continuously compounded one-month Treasury bill rate. The Barclays indices represent portfolios of long-term $(L)$ and intermediate (I) maturity corporate bonds with AAA, AA, and A ratings. The full sample period is 1989.02-2013.12 and the pre-crisis period is 1989.02-2007.07. $\bar{R}^{2}$ is the adjusted $R^{2}$. Heteroskedasticity-consistent standard errors are reported in parentheses. ${ }^{*},{ }^{* *}$, and ${ }^{* * *}$ denote statistical significance at the $10 \%$, $5 \%$, and $1 \%$ levels, respectively.

\begin{tabular}{|c|c|c|c|c|c|}
\hline & $x_{n+1, t}$ & $d e f_{t}$ & term $_{t}$ & $y_{t}$ & $\overline{\bar{R}^{2}}$ \\
\hline \multicolumn{6}{|c|}{ Panel A: Full sample } \\
\hline$A A A^{L}$ & $\begin{array}{c}0.07 \\
(0.13)\end{array}$ & $\begin{array}{c}0.17 \\
(0.78)\end{array}$ & $\begin{array}{c}0.53^{* * *} \\
(0.19)\end{array}$ & $\begin{array}{c}3.00 \\
(2.18)\end{array}$ & 0.015 \\
\hline$A A^{L}$ & $\begin{array}{c}0.05 \\
(0.11)\end{array}$ & $\begin{array}{c}0.76 \\
(0.58)\end{array}$ & $\begin{array}{c}0.55^{* * *} \\
(0.16)\end{array}$ & $\begin{array}{l}3.95^{* *} \\
(1.77)\end{array}$ & 0.037 \\
\hline$A^{L}$ & $\begin{array}{c}0.12 \\
(0.11)\end{array}$ & $\begin{array}{c}0.65 \\
(0.56)\end{array}$ & $\begin{array}{c}0.55^{* * *} \\
(0.16)\end{array}$ & $\begin{array}{l}3.60^{* *} \\
(1.68)\end{array}$ & 0.041 \\
\hline$A A A^{I}$ & $\begin{array}{l}0.13^{* *} \\
(0.06)\end{array}$ & $\begin{array}{c}0.20 \\
(0.21)\end{array}$ & $\begin{array}{c}0.26^{* * *} \\
(0.07)\end{array}$ & $\begin{array}{c}1.83^{* * *} \\
(0.68)\end{array}$ & 0.040 \\
\hline$A A^{I}$ & $\begin{array}{c}0.17^{* * *} \\
(0.06)\end{array}$ & $\begin{array}{c}0.34^{*} \\
(0.16)\end{array}$ & $\begin{array}{c}0.26^{* * *} \\
(0.07)\end{array}$ & $\begin{array}{c}2.09^{* * *} \\
(0.64)\end{array}$ & 0.067 \\
\hline$A^{I}$ & $\begin{array}{c}0.20^{* * *} \\
(0.07)\end{array}$ & $\begin{array}{c}0.38^{*} \\
(0.22)\end{array}$ & $\begin{array}{c}0.27^{* * *} \\
(0.08)\end{array}$ & $\begin{array}{c}2.01^{* * *} \\
(0.70)\end{array}$ & 0.072 \\
\hline \multicolumn{6}{|c|}{ Panel B: Pre-crisis } \\
\hline$A A A^{L}$ & $\begin{array}{c}0.10 \\
(0.07)\end{array}$ & $\begin{array}{c}0.21 \\
(0.37)\end{array}$ & $\begin{array}{c}0.45^{* * *} \\
(0.15)\end{array}$ & $\begin{array}{l}3.17^{* *} \\
(1.58)\end{array}$ & 0.023 \\
\hline$A A^{L}$ & $\begin{array}{c}0.07 \\
(0.07)\end{array}$ & $\begin{array}{c}0.38 \\
(0.39)\end{array}$ & $\begin{array}{c}0.47^{* * *} \\
(0.16)\end{array}$ & $\begin{array}{l}3.49^{* *} \\
(1.61)\end{array}$ & 0.021 \\
\hline$A^{L}$ & $\begin{array}{c}0.08 \\
(0.07)\end{array}$ & $\begin{array}{c}0.29 \\
(0.40)\end{array}$ & $\begin{array}{c}0.47^{* * *} \\
(0.16)\end{array}$ & $\begin{array}{l}3.35^{* *} \\
(1.58)\end{array}$ & 0.021 \\
\hline$A A A^{I}$ & $\begin{array}{l}0.15^{* *} \\
(0.07)\end{array}$ & $\begin{array}{c}0.18 \\
(0.19)\end{array}$ & $\begin{array}{c}0.26^{* * *} \\
(0.08)\end{array}$ & $\begin{array}{c}2.17^{* * *} \\
(0.77)\end{array}$ & 0.046 \\
\hline$A A^{I}$ & $\begin{array}{l}0.16^{* *} \\
(0.07)\end{array}$ & $\begin{array}{c}0.25 \\
(0.18)\end{array}$ & $\begin{array}{c}0.27^{* * *} \\
(0.08)\end{array}$ & $\begin{array}{c}2.33^{* * *} \\
(0.76)\end{array}$ & 0.056 \\
\hline$A^{I}$ & $\begin{array}{l}0.16^{* *} \\
(0.06)\end{array}$ & $\begin{array}{c}0.24 \\
(0.19)\end{array}$ & $\begin{array}{c}0.27^{* * *} \\
(0.08)\end{array}$ & $\begin{array}{c}2.19^{* * *} \\
(0.78)\end{array}$ & 0.052 \\
\hline
\end{tabular}


Table 7: Variance decomposition for unexpected excess bond returns

This table presents the decomposition of the variance of unexpected excess bond returns into the variance of interest rate news $\left(\tilde{x}_{y}\right)$, the variance of discount rate news $\left(\tilde{x}_{x}\right)$, and the covariance between these two news components. News components are extracted from the benchmark VAR(1) model presented in Section 4. The VAR state vector is given by $\left[x_{n, t+1}, d e f_{t+1}, t e r m_{t+1}, y_{t+1}\right]^{\prime}$, where $x_{n}$ denotes excess returns on the Barclays corporate bond index with average maturity $n$; def denotes the default spread; term is the term spread; and $y$ denotes the continuously compounded one-month Treasury bill rate. The Barclays indices represent portfolios of long-term $(L)$ and intermediate $(I)$ maturity corporate bonds with AAA, AA, and A ratings. The full sample period is 1989.02-2013.12 and the pre-crisis period is 1989.02-2007.07. The standard errors reported in parentheses are computed using the delta method. *, **, and ${ }^{* * *}$ denote statistical significance at the $10 \%, 5 \%$, and $1 \%$ levels, respectively.

\begin{tabular}{ccccccc}
\hline \hline & $A A A^{L}$ & $A A^{L}$ & $A^{L}$ & $A A A^{I}$ & $A A^{I}$ & $A^{I}$ \\
\hline \multicolumn{7}{c}{ Panel A: Full sample } \\
\hline $\operatorname{Var}\left[\tilde{x}_{y}\right]$ & $0.30^{* *}$ & 0.38 & 0.21 & 0.45 & 0.71 & $0.65^{*}$ \\
$2 \operatorname{Cov}\left[\tilde{x}_{y}, \tilde{x}_{x}\right]$ & $(0.13)$ & $(0.35)$ & $(0.14)$ & $(0.35)$ & $(0.48)$ & $(0.35)$ \\
& 0.15 & -0.39 & -0.01 & -0.14 & -0.78 & -0.55 \\
$\operatorname{Var}\left[\tilde{x}_{x}\right]$ & $(0.20)$ & $(0.86)$ & $(0.41)$ & $(0.67)$ & $(1.05)$ & $(0.85)$ \\
& $0.55^{* * *}$ & $1.02^{*}$ & $0.80^{* *}$ & $0.69^{*}$ & $1.07^{*}$ & 0.90 \\
& $(0.18)$ & $(0.55)$ & $(0.32)$ & $(0.38)$ & $(0.63)$ & $(0.57)$ \\
\hline \multicolumn{7}{c}{ Panel B: Pre-crisis } \\
$2 \operatorname{Var}\left[\tilde{x}_{y}\right]$ & $0.10^{* *}$ & $0.14^{* *}$ & $0.12^{* * *}$ & 0.31 & 0.44 & 0.41 \\
& $(0.05)$ & $(0.07)$ & $(0.04)$ & $(0.25)$ & $(0.36)$ & $(0.27)$ \\
$\operatorname{Var}\left[\tilde{x}_{y}, \tilde{x}_{x}\right]$ & 0.05 & -0.04 & 0.03 & -0.27 & -0.51 & -0.37 \\
& $0.20)$ & $(0.24)$ & $(0.19)$ & $(0.43)$ & $(0.59)$ & $(0.50)$ \\
& $0.85^{* * *}$ & $0.90^{* * *}$ & $0.85^{* * *}$ & $0.97^{* * *}$ & $1.07^{* *}$ & $0.97^{* *}$ \\
& $(0.22)$ & $(0.24)$ & $(0.20)$ & $(0.37)$ & $(0.43)$ & $(0.40)$ \\
\hline \hline
\end{tabular}


Table 8: VAR-based responses of unexpected excess bond returns to monetary policy shocks

This table reports presents the estimated response of unexpected excess bond returns $\left(\tilde{x}_{n}^{M P}\right)$ and the two news components (interest rate news, $\tilde{x}_{y}^{M P}$, and discount rate news, $\tilde{x}_{x}^{M P}$ ) to monetary policy shocks (unexpected change in the FFR, $M P$ ). News components are extracted from the benchmark $\operatorname{VAR}(1)$ presented in Section 4 . The VAR state vector is given by $\left[x_{n, t+1}, d e f_{t+1}, t e r m_{t+1}, y_{t+1}\right]^{\prime}$, where $x_{n}$ denotes excess returns on the Barclays corporate bond index with average maturity $n$; def denotes the default spread; term is the term spread; and $y$ denotes the continuously compounded one-month Treasury bill rate. The Barclays indices represent portfolios of long-term $(L)$ and intermediate $(I)$ maturity corporate bonds with AAA, AA, and A ratings. The full sample period is 1989.02-2013.12 and the pre-crisis period is 1989.02-2007.07. The standard errors reported in parentheses are computed using the delta method. *, **, and ${ }^{* * *}$ denote statistical significance at the $10 \%, 5 \%$, and $1 \%$ levels, respectively.

\begin{tabular}{lcccccc}
\hline \hline & $A A A^{L}$ & $A A^{L}$ & $A^{L}$ & $A A A^{I}$ & $A A^{I}$ & $A^{I}$ \\
\hline \multicolumn{7}{c}{ Panel A: Full sample } \\
\hline$\tilde{x}_{n}^{M P}$ & -0.45 & $-0.84^{*}$ & $-1.46^{* * *}$ & $-1.45^{* * *}$ & $-1.77^{* * *}$ & $-1.86^{* * *}$ \\
& $(0.60)$ & $(0.48)$ & $(0.49)$ & $(0.21)$ & $(0.21)$ & $(0.23)$ \\
$\tilde{x}_{y}^{M P}$ & -0.78 & 0.49 & $1.20^{* *}$ & $0.86^{* * *}$ & $1.39^{* * *}$ & $1.48^{* * *}$ \\
& $(0.76)$ & $(0.77)$ & $(0.59)$ & $(0.33)$ & $(0.40)$ & $(0.46)$ \\
$\tilde{x}_{x}^{M P}$ & $1.22^{* *}$ & 0.35 & 0.26 & $0.59^{* *}$ & 0.38 & 0.37 \\
& $(0.50)$ & $(0.73)$ & $(0.56)$ & $(0.26)$ & $(0.34)$ & $(0.40)$ \\
\hline \multicolumn{7}{c}{ Panel B: Pre-crisis } \\
$\tilde{x}_{n}^{M P}$ & $-3.74^{* * *}$ & $-3.81^{* * *}$ & $-4.61^{* * *}$ & $-2.29^{* * *}$ & $-2.51^{* * *}$ & $-2.82^{* * *}$ \\
$\tilde{x}_{y}^{M P}$ & $(0.46)$ & $(0.47)$ & $(0.46)$ & $(0.22)$ & $(0.22)$ & $(0.23)$ \\
& 0.29 & 0.17 & 1.00 & 0.33 & 0.51 & 0.95 \\
$\tilde{x}_{x}^{M P}$ & $(0.62)$ & $(0.70)$ & $(0.61)$ & $(0.54)$ & $(0.62)$ & $(0.65)$ \\
& $3.45^{* * *}$ & $3.64^{* * *}$ & $3.62^{* * *}$ & $1.96^{* * *}$ & $2.00^{* * *}$ & $1.87^{* * *}$ \\
& $(0.52)$ & $(0.62)$ & $(0.53)$ & $(0.44)$ & $(0.53)$ & $(0.53)$ \\
\hline \hline
\end{tabular}


Table 9: Variance decomposition for unexpected excess bond returns: alternative bond return decomposition

This table presents the decomposition of the variance of unexpected excess bond returns into the variance of interest rate news $\left(\tilde{x}_{y}\right)$, the variance of term premium news $\left(\tilde{x}_{x}^{G}\right)$, the variance of credit risk premium news $\left(\tilde{x}_{x}^{C}\right)$ and the covariances between these three news components. News components are extracted from the benchmark VAR(1) model presented in Appendix C. The VAR state vector is given by $\left[x_{n, t+1}, x_{n, t+1}^{G}, d e f_{t+1}, \text { term }_{t+1}, y_{t+1}\right]^{\prime}$, where $x_{n}$ denotes excess returns on the Barclays corporate bond index with average maturity $n ; x_{n, t+1}^{G}$ denotes the excess return (relative to the risk-free rate) of a Treasury bond with average maturity $n$; def denotes the default spread; term is the term spread; and $y$ denotes the continuously compounded one-month Treasury bill rate. The Barclays indices represent portfolios of long-term $(L)$ and intermediate $(I)$ maturity corporate bonds with AAA, AA, and A ratings. The full sample period is $1989.02-2013.12$ and the pre-crisis period is $1989.02-2007.07$. The standard errors reported in parentheses are computed using the delta method. *, **, and *** denote statistical significance at the $10 \%, 5 \%$, and $1 \%$ levels, respectively.

\begin{tabular}{|c|c|c|c|c|c|c|}
\hline & $\overline{4 A^{L}}$ & $A A^{L}$ & $\overline{A^{L}}$ & $A A A^{I}$ & $A A^{I}$ & $A^{I}$ \\
\hline \multicolumn{7}{|c|}{ Panel A: Full sample } \\
\hline $\operatorname{Var}\left[\tilde{x}_{y}\right]$ & $\begin{array}{l}0.26 \\
0.24)\end{array}$ & $\begin{array}{c}0.26 \\
(0.27)\end{array}$ & $\begin{array}{l}0.12^{*} \\
(0.07)\end{array}$ & $\begin{array}{c}0.26 \\
(0.18)\end{array}$ & $\begin{array}{c}0.42 \\
(0.28)\end{array}$ & $\begin{array}{c}0.39^{*} \\
(0.21)\end{array}$ \\
\hline $2 \operatorname{Cov}\left[\tilde{x}_{x}^{G}, \tilde{x}_{y}\right.$ & $\begin{array}{l}0.04 \\
0.27)\end{array}$ & $\begin{array}{c}0.07 \\
(0.36)\end{array}$ & $\begin{array}{c}0.1 \\
(0.1\end{array}$ & $\begin{array}{l}-0.05 \\
(0.34)\end{array}$ & $\begin{array}{c}-0.11 \\
(0.51)\end{array}$ & $\begin{array}{c}0.06 \\
(0.30)\end{array}$ \\
\hline $2 \operatorname{Cov}\left[\tilde{x}_{x}^{C}, \tilde{x}_{y}\right]$ & $\begin{array}{l}.04 \\
37)\end{array}$ & $\begin{array}{l}-0.35 \\
(0.42)\end{array}$ & $\begin{array}{l}-0 . \\
(0.1\end{array}$ & $\begin{array}{c}0.03 \\
(0.19)\end{array}$ & $\begin{array}{c}-0.32 \\
(0.26)\end{array}$ & $\begin{array}{c}-0.29 \\
(0.29)\end{array}$ \\
\hline $\operatorname{Var}\left[\tilde{x}_{x}^{G}\right]$ & & $(0.2$ & & $\begin{array}{l}0.44 \\
(0.29)\end{array}$ & $\begin{array}{c}0.47 \\
(0.30)\end{array}$ & $\begin{array}{c}0.36^{*} \\
(0.22)\end{array}$ \\
\hline $2 \operatorname{Cov}\left[\tilde{x}_{x}^{G}, \tilde{x}_{x}^{C}\right]$ & $\begin{array}{c}0.26 \\
(0.19)\end{array}$ & $\begin{array}{c}0.18 \\
(0.49)\end{array}$ & & $\begin{array}{c}0.26^{* * *} \\
(0.10)\end{array}$ & $\begin{array}{c}0.34 \\
(0.26)\end{array}$ & $\begin{array}{c}0.25 \\
(0.25)\end{array}$ \\
\hline $\operatorname{Var}\left[\tilde{x}_{x}^{C}\right]$ & $\begin{array}{l}0.08 \\
(0.19)\end{array}$ & $\begin{array}{c}0.32 \\
(0.23)\end{array}$ & $\begin{array}{c}0.19 \\
(0.24)\end{array}$ & $\begin{array}{c}0.06 \\
(0.05)\end{array}$ & $\begin{array}{c}0.21 \\
(0.18)\end{array}$ & $\begin{array}{c}0.23 \\
(0.21)\end{array}$ \\
\hline \multicolumn{7}{|c|}{ Panel B: Pre-crisis } \\
\hline $\operatorname{Vir}[\tilde{r}]$ & $\begin{array}{l}10^{*} \\
05)\end{array}$ & & & $\begin{array}{c}0.30 \\
(0.26)\end{array}$ & $\begin{array}{c}0.42 \\
(0.36)\end{array}$ & $\begin{array}{c}0.40 \\
(0.29)\end{array}$ \\
\hline $2 C \rho v[\tilde{x}$ & $\begin{array}{l}0.10 \\
(0.15)\end{array}$ & $\begin{array}{c}0.12 \\
(0.16)\end{array}$ & & $\begin{array}{l}-0.23 \\
(0.47)\end{array}$ & $\begin{array}{c}-0.29 \\
(0.56)\end{array}$ & $\begin{array}{l}-0.16 \\
(0.49)\end{array}$ \\
\hline $2 \operatorname{Cov}\left[\tilde{x}_{x}^{C}\right.$, & $\begin{array}{c}0.00 \\
(0.08)\end{array}$ & $\begin{array}{l}-0.08 \\
(0.12)\end{array}$ & $\begin{array}{r}0.0 \\
(0.0\end{array}$ & $\begin{array}{c}0.04 \\
(0.17)\end{array}$ & $\begin{array}{l}-0.11 \\
(0.15)\end{array}$ & $\begin{array}{c}-0.10 \\
(0.22)\end{array}$ \\
\hline $\operatorname{Var}\left[\tilde{x}_{x}^{G}\right]$ & $\begin{array}{c}0.64^{* *} \\
(0.29)\end{array}$ & $\begin{array}{c}0.61^{* *} \\
(0.28)\end{array}$ & $\begin{array}{l}0.59^{* *} \\
(0.27)\end{array}$ & $\begin{array}{l}0.71^{*} \\
(0.40)\end{array}$ & $\begin{array}{c}0.70^{*} \\
(0.39)\end{array}$ & $\begin{array}{l}0.69^{*} \\
(0.40)\end{array}$ \\
\hline $\operatorname{Cov}[3$ & $\begin{array}{c}0.10 \\
(0.18)\end{array}$ & $\begin{array}{c}0.10 \\
(0.22)\end{array}$ & $\begin{array}{c}0.11 \\
(0.20)\end{array}$ & $\begin{array}{c}0.16 \\
(0.13)\end{array}$ & $\begin{array}{l}0.25^{*} \\
(0.13)\end{array}$ & $\begin{array}{c}0.16 \\
(0.16)\end{array}$ \\
\hline $\operatorname{Var}\left[\tilde{x}_{x}^{C}\right]$ & $\begin{array}{c}0.06 \\
(0.06)\end{array}$ & $\begin{array}{c}0.13 \\
(0.09)\end{array}$ & $\begin{array}{c}0.08 \\
(0.08)\end{array}$ & $\begin{array}{c}0.01 \\
(0.03)\end{array}$ & $\begin{array}{c}0.03 \\
(0.04)\end{array}$ & $\begin{array}{c}0.02 \\
(0.05)\end{array}$ \\
\hline
\end{tabular}


Table 10: VAR-based responses of unexpected excess bond returns to monetary policy shocks: alternative bond return decomposition

This table reports presents the estimated response of unexpected excess bond returns $\left(\tilde{x}_{n}^{M P}\right)$ and the three news components (interest rate news, $\tilde{x}_{y}^{M P}$; term premium news, $\tilde{x}_{x}^{G M P}$; and credit risk premium news, $\tilde{x}_{x}^{C M P}$ ) to monetary policy shocks (unexpected change in the FFR, $M P$ ). News components are extracted from the benchmark VAR(1) model presented in Appendix C. The VAR state vector is given by $\left[x_{n, t+1}, x_{n, t+1}^{G}, \text { de }_{t+1}, \text { term } m_{t+1}, y_{t+1}\right]^{\prime}$, where $x_{n}$ denotes excess returns on the Barclays corporate bond index with average maturity $n ; x_{n, t+1}^{G}$ denotes the excess return (relative to the risk-free rate) of a Treasury bond with average maturity $n$; def denotes the default spread; term is the term spread; and $y$ denotes the continuously compounded one-month Treasury bill rate. The Barclays indices represent portfolios of long-term $(L)$ and intermediate $(I)$ maturity corporate bonds with AAA, AA, and A ratings. The full sample period is 1989.02-2013.12 and the pre-crisis period is 1989.02-2007.07. The standard errors reported in parentheses are computed using the delta method. *, **, and *** denote statistical significance at the $10 \%, 5 \%$, and $1 \%$ levels, respectively.

\begin{tabular}{|c|c|c|c|c|c|c|}
\hline & $\overline{\overline{A A A^{L}}}$ & $\overline{A A A^{L}}$ & 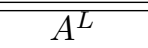 & $\overline{A A A A^{I}}$ & $A A^{I}$ & $A^{I}$ \\
\hline \multicolumn{7}{|c|}{ Panel A: Full sample } \\
\hline$\tilde{x}_{n}^{M P}$ & $\begin{array}{l}-0.20 \\
(0.76)\end{array}$ & $\begin{array}{l}-0.78 \\
(0.49)\end{array}$ & $\begin{array}{c}-1.35^{* * *} \\
(0.55)\end{array}$ & $\begin{array}{c}-1.34^{* * *} \\
(0.25)\end{array}$ & $\begin{array}{c}-1.72^{* * *} \\
(0.24)\end{array}$ & $\begin{array}{c}-1.78^{* * *} \\
(0.27)\end{array}$ \\
\hline$\tilde{x}_{y}^{M P}$ & $\begin{array}{c}-1.32^{* *} \\
(0.64)\end{array}$ & $\begin{array}{c}0.33 \\
(0.71)\end{array}$ & $\begin{array}{l}0.80^{*} \\
(0.45)\end{array}$ & $\begin{array}{l}0.79^{* *} \\
(0.35)\end{array}$ & $\begin{array}{c}1.36^{* * *} \\
(0.39)\end{array}$ & $\begin{array}{c}1.46^{* * *} \\
(0.44)\end{array}$ \\
\hline$\tilde{x}_{x}^{G M P}$ & $\begin{array}{l}0.98^{*} \\
(0.50)\end{array}$ & $\begin{array}{c}0.76 \\
(0.61)\end{array}$ & $\begin{array}{c}0.92 \\
(0.60)\end{array}$ & $\begin{array}{c}0.32 \\
(0.39)\end{array}$ & $\begin{array}{c}0.35 \\
(0.35)\end{array}$ & $\begin{array}{c}0.38 \\
(0.33)\end{array}$ \\
\hline$\tilde{x}_{x}^{C M P}$ & $\begin{array}{c}0.54 \\
(0.61)\end{array}$ & $\begin{array}{l}-0.31 \\
(0.50)\end{array}$ & $\begin{array}{l}-0.37 \\
(0.47)\end{array}$ & $\begin{array}{c}0.24 \\
(0.18)\end{array}$ & $\begin{array}{l}0.004 \\
(0.18)\end{array}$ & $\begin{array}{l}-0.06 \\
(0.19)\end{array}$ \\
\hline \multicolumn{7}{|c|}{ Panel B: Pre-crisis } \\
\hline$\tilde{x}_{n}^{M H}$ & $\begin{array}{c}-3.76^{* * *} \\
(0.46)\end{array}$ & $\begin{array}{c}-3.83^{* * *} \\
(0.47)\end{array}$ & $\begin{array}{c}-4.60^{* * *} \\
(0.46)\end{array}$ & $\begin{array}{c}-2.28^{* * *} \\
(0.22)\end{array}$ & $\begin{array}{c}-2.51^{* * *} \\
(0.22)\end{array}$ & $\begin{array}{c}-2.82^{* * *} \\
(0.23)\end{array}$ \\
\hline$\tilde{x}_{y}^{M P}$ & $\begin{array}{c}0.41 \\
(0.62)\end{array}$ & $\begin{array}{c}0.32 \\
(0.68)\end{array}$ & $\begin{array}{l}1.03^{*} \\
(0.62)\end{array}$ & $\begin{array}{c}0.39 \\
(0.52)\end{array}$ & $\begin{array}{c}0.52 \\
(0.57)\end{array}$ & $\begin{array}{c}0.97 \\
(0.63)\end{array}$ \\
\hline$\tilde{x}_{x}^{G M P}$ & $\begin{array}{c}2.76^{* * *} \\
(0.67)\end{array}$ & $\begin{array}{c}2.77^{* * *} \\
(0.69)\end{array}$ & $\begin{array}{c}2.79^{* * *} \\
(0.69)\end{array}$ & $\begin{array}{c}1.65^{* * *} \\
(0.55)\end{array}$ & $\begin{array}{c}1.69^{* * *} \\
(0.54)\end{array}$ & $\begin{array}{c}1.67^{* * *} \\
(0.57)\end{array}$ \\
\hline$\tilde{x}_{x}^{C M P}$ & $\begin{array}{c}0.59 \\
(0.51)\end{array}$ & $\begin{array}{c}0.75 \\
(0.68)\end{array}$ & $\begin{array}{c}0.79 \\
(0.64)\end{array}$ & $\begin{array}{c}0.24 \\
(0.21)\end{array}$ & $\begin{array}{c}0.30 \\
(0.21)\end{array}$ & $\begin{array}{l}0.18 \\
(0.24)\end{array}$ \\
\hline
\end{tabular}


Table A.1: VAR-based response of unexpected excess bond returns to monetary policy shocks: alternative state vector 1 (adding $d p$ )

This table reports presents the estimated response of unexpected excess bond returns $\left(\tilde{x}_{n}^{M P}\right)$ and the two news components (interest rate news, $\tilde{x}_{y}^{M P}$, and discount rate news, $\tilde{x}_{x}^{M P}$ ) to monetary policy shocks (unexpected change in the FFR, $M P$ ). News components are extracted from a $\operatorname{VAR}(1)$ model where the state vector is given by $\left[x_{n, t+1}, d e f_{t+1}, t e r m_{t+1}, y_{t+1}, d p_{t+1}\right]^{\prime}$, where $x_{n}$ denotes excess returns on the Barclays corporate bond index with average maturity $n$; def denotes the default spread; term is the term spread; $y$ denotes the continuously compounded one-month Treasury bill rate; and $d p$ is the log dividend-to-price ratio for the S\& P500 stock market index. The Barclays indices represent portfolios of long-term $(L)$ and intermediate $(I)$ maturity corporate bonds with AAA, AA, and A ratings. The sample period is 1989.02-2007.07. The standard errors reported in parentheses are computed using the delta method. ${ }^{*}, * *$, and ${ }^{* * *}$ denote statistical significance at the $10 \%, 5 \%$, and $1 \%$ levels, respectively.

\begin{tabular}{lcccccc}
\hline \hline & $A A A^{L}$ & $A A^{L}$ & $A^{L}$ & $A A A^{I}$ & $A A^{I}$ & $A^{I}$ \\
\hline$\tilde{x}_{n}^{M P}$ & $-3.79^{* * *}$ & $-3.86^{* * *}$ & $-4.64^{* * *}$ & $-2.34^{* * *}$ & $-2.56^{* * *}$ & $-2.85^{* * *}$ \\
& $(0.45)$ & $(0.46)$ & $(0.45)$ & $(0.22)$ & $(0.22)$ & $(0.23)$ \\
$\tilde{x}_{y}^{M P}$ & 0.39 & 0.52 & 0.86 & 0.47 & 0.70 & $1.06^{*}$ \\
& $(0.77)$ & $(0.77)$ & $(0.88)$ & $(0.46)$ & $(0.54)$ & $(0.61)$ \\
$\tilde{x}_{x}^{M P}$ & $3.40^{* * *}$ & $3.34^{* * *}$ & $3.78^{* * *}$ & $1.87^{* * *}$ & $1.86^{* * *}$ & $1.79^{* * *}$ \\
& $(0.64)$ & $(0.69)$ & $(0.77)$ & $(0.39)$ & $(0.48)$ & $(0.50)$ \\
\hline \hline
\end{tabular}


Table A.2: VAR-based response of unexpected excess bond returns to monetary policy shocks: alternative state vector 2 (adding $A N F C I$ )

This table reports presents the estimated response of unexpected excess bond returns $\left(\tilde{x}_{n}^{M P}\right)$ and the two news components (interest rate news, $\tilde{x}_{y}^{M P}$, and discount rate news, $\tilde{x}_{x}^{M P}$ ) to monetary policy shocks (unexpected change in the FFR, $M P$ ). News components are extracted from a $\operatorname{VAR}(1)$ model where the state vector is given by $\left[x_{n, t+1}, d e f_{t+1}, \operatorname{term}_{t+1}, y_{t+1}, A N F C I_{t+1}\right]^{\prime}$, where $x_{n}$ denotes excess returns on the Barclays corporate bond index with average maturity $n$; def denotes the default spread; term is the term spread; $y$ denotes the continuously compounded one-month Treasury bill rate; and $A N F C I$ is the Chicago Fed Adjusted National Financial Conditions Index. The Barclays indices represent portfolios of long-term $(L)$ and intermediate $(I)$ maturity corporate bonds with AAA, AA, and A ratings. The sample period is 1989.02-2007.07. The standard errors reported in parentheses are computed using the delta method. ${ }^{*},{ }^{* *}$, and ${ }^{* * *}$ denote statistical significance at the $10 \%, 5 \%$, and $1 \%$ levels, respectively.

\begin{tabular}{lcccccc}
\hline \hline & $A A A^{L}$ & $A A^{L}$ & $A^{L}$ & $A A A^{I}$ & $A A^{I}$ & $A^{I}$ \\
\hline$\tilde{x}_{n}^{M P}$ & $-3.66^{* * *}$ & $-3.73^{* * *}$ & $-4.55^{* * *}$ & $-2.26^{* * *}$ & $-2.48^{* * *}$ & $-2.80^{* * *}$ \\
& $(0.46)$ & $(0.47)$ & $(0.46)$ & $(0.22)$ & $(0.22)$ & $(0.23)$ \\
$\tilde{x}_{y}^{M P}$ & 0.27 & 0.10 & $0.98^{*}$ & 0.34 & 0.47 & 0.95 \\
& $(0.60)$ & $(0.68)$ & $(0.59)$ & $(0.51)$ & $(0.59)$ & $(0.61)$ \\
$\tilde{x}_{x}^{M P}$ & $3.39^{* * *}$ & $3.63^{* * *}$ & $3.57^{* * *}$ & $1.93^{* * *}$ & $2.02^{* * *}$ & $1.85^{* * *}$ \\
& $(0.51)$ & $(0.63)$ & $(0.52)$ & $(0.43)$ & $(0.52)$ & $(0.52)$ \\
\hline \hline
\end{tabular}


Table A.3: VAR-based response of unexpected excess bond returns to monetary policy shocks: alternative state vector 3 (adding $C F N A I$ )

This table reports presents the estimated response of unexpected excess bond returns $\left(\tilde{x}_{n}^{M P}\right)$ and the two news components (interest rate news, $\tilde{x}_{y}^{M P}$, and discount rate news, $\tilde{x}_{x}^{M P}$ ) to monetary policy shocks (unexpected change in the FFR, $M P$ ). News components are extracted from a $\operatorname{VAR}(1)$ model where the state vector is given by $\left[x_{n, t+1}, d e f_{t+1}, t_{e r m_{t+1}}, y_{t+1}, C F N A I_{t+1}\right]^{\prime}$, where $x_{n}$ denotes excess returns on the Barclays corporate bond index with average maturity $n$; def denotes the default spread; term is the term spread; $y$ denotes the continuously compounded one-month Treasury bill rate; and CFNAI is the Chicago Fed National Activity Index. The Barclays indices represent portfolios of long-term $(L)$ and intermediate $(I)$ maturity corporate bonds with AAA, AA, and A ratings. The sample period is 1989.02-2007.07. The standard errors reported in parentheses are computed using the delta method. ${ }^{*}, * *$, and ${ }^{* * *}$ denote statistical significance at the $10 \%, 5 \%$, and $1 \%$ levels, respectively.

\begin{tabular}{lcccccc}
\hline \hline & $A A A^{L}$ & $A A^{L}$ & $A^{L}$ & $A A A^{I}$ & $A A^{I}$ & $A^{I}$ \\
\hline$\tilde{x}_{n}^{M P}$ & $-3.31^{* * *}$ & $-3.39^{* * *}$ & $-4.17^{* * *}$ & $-2.06^{* * *}$ & $-2.28^{* * *}$ & $-2.56^{* * *}$ \\
& $(0.52)$ & $(0.52)$ & $(0.51)$ & $(0.26)$ & $(0.26)$ & $(0.27)$ \\
$\tilde{x}_{y}^{M P}$ & 0.29 & 0.17 & $0.99^{*}$ & 0.33 & 0.51 & 0.94 \\
& $(0.61)$ & $(0.69)$ & $(0.60)$ & $(0.53)$ & $(0.61)$ & $(0.63)$ \\
$\tilde{x}_{x}^{M P}$ & $3.02^{* * *}$ & $3.21^{* * *}$ & $3.17^{* * *}$ & $1.73^{* * *}$ & $1.77^{* * *}$ & $1.62^{* * *}$ \\
& $(0.52)$ & $(0.61)$ & $(0.54)$ & $(0.42)$ & $(0.51)$ & $(0.51)$ \\
\hline \hline
\end{tabular}


Table A.4: VAR-based response of unexpected excess bond returns to monetary policy shocks: higher order VAR

This table reports presents the estimated response of unexpected excess bond returns $\left(\tilde{x}_{n}^{M P}\right)$ and the two news components (interest rate news, $\tilde{x}_{y}^{M P}$, and discount rate news, $\tilde{x}_{x}^{M P}$ ) to monetary policy shocks (unexpected change in the FFR, $M P$ ). News components are extracted from a $\operatorname{VAR}(3)$ model where the state vector is given $\left[x_{n, t+1}, \operatorname{de}_{t+1}, \text { term }_{t+1}, y_{t+1}\right]^{\prime}$, where $x_{n}$ denotes excess returns on the Barclays corporate bond index with average maturity $n$; def denotes the default spread; term is the term spread; and $y$ denotes the continuously compounded one-month Treasury bill rate. The Barclays indices represent portfolios of long-term $(L)$ and intermediate $(I)$ maturity corporate bonds with AAA, AA, and A ratings. The sample period is 1989.02-2007.07. The standard errors reported in parentheses are computed using the delta method. ${ }^{*},{ }^{* *}$, and ${ }^{* * *}$ denote statistical significance at the $10 \%, 5 \%$, and $1 \%$ levels, respectively.

\begin{tabular}{lcccccc}
\hline \hline & $A A A^{L}$ & $A A^{L}$ & $A^{L}$ & $A A A^{I}$ & $A A^{I}$ & $A^{I}$ \\
\hline$\tilde{x}_{n}^{M P}$ & $-3.88^{* * *}$ & $-4.01^{* * *}$ & $-4.65^{* * *}$ & $-2.21^{* * *}$ & $-2.55^{* * *}$ & $-2.83^{* * *}$ \\
& $(0.45)$ & $(0.47)$ & $(0.48)$ & $(0.26)$ & $(0.24)$ & $(0.26)$ \\
$\tilde{x}_{y}^{M P}$ & 0.05 & 0.21 & 0.71 & -0.02 & 0.10 & 0.42 \\
& $(0.57)$ & $(0.57)$ & $(0.50)$ & $(0.52)$ & $(0.62)$ & $(0.63)$ \\
$\tilde{x}_{x}^{M P}$ & $3.82^{* * *}$ & $3.80^{* * *}$ & $3.94^{* * *}$ & $2.24^{* * *}$ & $2.45^{* * *}$ & $2.41^{* * *}$ \\
& $(0.64)$ & $(0.61)$ & $(0.54)$ & $(0.49)$ & $(0.59)$ & $(0.59)$ \\
\hline \hline
\end{tabular}


Table A.5: VAR-based response of unexpected excess bond returns to monetary policy shocks: consol bonds

This table reports presents the estimated response of unexpected excess bond returns $\left(\tilde{x}_{n}^{M P}\right)$ and the two news components (interest rate news, $\tilde{x}_{y}^{M P}$, and discount rate news, $\tilde{x}_{x}^{M P}$ ) to monetary policy shocks (unexpected change in the FFR, $M P$ ). News components are extracted from a $\operatorname{VAR}(1)$ model where the state vector is given by $\left[x_{n, t+1}, \text { de }_{t+1}, \text { term }_{t+1}, y_{t+1}\right]^{\prime}$, where $x_{n}$ denotes excess returns on the Barclays corporate bond index with infinite average maturity; def denotes the default spread; term is the term spread; and $y$ denotes the continuously compounded one-month Treasury bill rate. The relevant formulas for consol bonds are used. The Barclays indices represent portfolios of corporate bonds with AAA, AA, and A ratings. The sample period is 1989.02-2007.07. The standard errors reported in parentheses are computed using the delta method. ${ }^{*},{ }^{* *}$, and ${ }^{* * *}$ denote statistical significance at the $10 \%, 5 \%$, and $1 \%$ levels, respectively.

\begin{tabular}{lccc}
\hline \hline & $A A A^{L}$ & $A A^{L}$ & $A^{L}$ \\
\hline$\tilde{x}_{n}^{M P}$ & $-3.74^{* * *}$ & $-3.81^{* * *}$ & $-4.61^{* * *}$ \\
& $(0.46)$ & $(0.47)$ & $(0.46)$ \\
$\tilde{x}_{y}^{M P}$ & 0.29 & 0.17 & 1.00 \\
& $(0.62)$ & $(0.70)$ & $(0.61)$ \\
$\tilde{x}_{x}^{M P}$ & $3.45^{* * *}$ & $3.64^{* * *}$ & $3.62^{* * *}$ \\
& $(0.52)$ & $(0.62)$ & $(0.53)$ \\
\hline \hline
\end{tabular}


Table A.6: VAR-based response of unexpected excess bond returns to monetary policy shocks: alternative identification (discount rate news as residual)

This table reports presents the estimated response of unexpected excess bond returns $\left(\tilde{x}_{n}^{M P}\right)$ and the two news components (interest rate news, $\tilde{x}_{y}^{M P}$, and discount rate news, $\tilde{x}_{x}^{M P}$ ) to monetary policy shocks (unexpected change in the FFR, $M P$ ). News components are extracted from a $\operatorname{VAR}(1)$ model where the state vector is given by $\left[x_{n, t+1}, \text { de }_{t+1}, \text { term }_{t+1}, y_{t+1}\right]^{\prime}$, where $x_{n}$ denotes excess returns on the Barclays corporate bond index with average maturity $n$; def denotes the default spread; term is the term spread; and $y$ denotes the continuously compounded one-month Treasury bill rate. Discount rate news are backed out as the residual component of the decomposition. The Barclays indices represent portfolios of long-term $(L)$ and intermediate $(I)$ maturity corporate bonds with AAA, AA, and A ratings. The sample period is 1989.02-2007.07. The standard errors reported in parentheses are computed using the delta method. ${ }^{*}, * *$, and ${ }^{* * *}$ denote statistical significance at the $10 \%, 5 \%$, and $1 \%$ levels, respectively.

\begin{tabular}{lcccccc}
\hline \hline & $A A A^{L}$ & $A A^{L}$ & $A^{L}$ & $A A A^{I}$ & $A A^{I}$ & $A^{I}$ \\
\hline$\tilde{x}_{n}^{M P}$ & $-3.74^{* * *}$ & $-3.81^{* * *}$ & $-4.61^{* * *}$ & $-2.29^{* * *}$ & $-2.51^{* * *}$ & $-2.82^{* * *}$ \\
& $(0.46)$ & $(0.47)$ & $(0.46)$ & $(0.22)$ & $(0.22)$ & $(0.23)$ \\
$\tilde{x}_{y}^{M P}$ & 0.74 & 0.74 & 0.78 & 0.84 & 0.84 & 0.88 \\
& $(0.64)$ & $(0.63)$ & $(0.64)$ & $(0.54)$ & $(0.53)$ & $(0.55)$ \\
$\tilde{x}_{x}^{M P}$ & $2.99^{* * *}$ & $3.06^{* * *}$ & $3.83^{* * *}$ & $1.45^{* * *}$ & $1.68^{* * *}$ & $1.94^{* * *}$ \\
& $(0.45)$ & $(0.47)$ & $(0.49)$ & $(0.40)$ & $(0.40)$ & $(0.42)$ \\
\hline \hline
\end{tabular}


Table A.7: VAR-based responses of unexpected excess bond returns to monetary policy shocks: lagged monetary policy shocks

This table reports presents the estimated response of unexpected excess bond returns $\left(\tilde{x}_{n}^{L M P}\right)$ and the two news components (interest rate news, $\tilde{x}_{y}^{L M P}$, and discount rate news, $\tilde{x}_{x}^{L M P}$ ) to one-period lagged monetary policy shocks (lagged unexpected change in the FFR, $L M P$ ). News components are extracted from a $\operatorname{VAR}(1)$ model where the state vector is given by $\left[x_{n, t+1}, d e f_{t+1}, t e r m_{t+1}, y_{t+1}\right]^{\prime}$, where $x_{n}$ denotes excess returns on the Barclays corporate bond index with average maturity $n$; def denotes the default spread; term is the term spread; and $y$ denotes the continuously compounded one-month Treasury bill rate. The Barclays indices represent portfolios of long-term $(L)$ and intermediate $(I)$ maturity corporate bonds with AAA, AA, and A ratings. The sample period is 1989.02-2007.07. The standard errors reported in parentheses are computed using the delta method. ${ }^{*},{ }^{* *}$, and ${ }^{* * *}$ denote statistical significance at the $10 \%, 5 \%$, and $1 \%$ levels, respectively.

\begin{tabular}{lcccccc}
\hline \hline & $A A A^{L}$ & $A A^{L}$ & $A^{L}$ & $A A A^{I}$ & $A A^{I}$ & $A^{I}$ \\
\hline$\tilde{x}_{n}^{L M P}$ & $-1.41^{* * *}$ & $-1.63^{* * *}$ & $-1.75^{* * *}$ & $-0.78^{* * *}$ & $-1.02^{* * *}$ & $-0.92^{* * *}$ \\
$\tilde{x}_{y}^{L M P}$ & $(0.52)$ & $(0.54)$ & $(0.57)$ & $(0.27)$ & $(0.30)$ & $(0.29)$ \\
& -0.24 & -0.01 & 0.53 & -0.18 & -0.10 & 0.00 \\
$\tilde{x}_{x}^{L M P}$ & $(0.49)$ & $(0.59)$ & $(0.47)$ & $(0.45)$ & $(0.54)$ & $(0.50)$ \\
& $1.17^{* *}$ & $1.64^{* *}$ & $1.22^{* *}$ & $0.96^{* *}$ & $1.13^{* *}$ & $0.93^{* *}$ \\
& $(0.55)$ & $(0.64)$ & $(0.60)$ & $(0.43)$ & $(0.51)$ & $(0.46)$ \\
\hline \hline
\end{tabular}


Table A.8: VAR-based responses of unexpected excess bond returns to monetary policy shocks: Romer and Romer (2004) monetary policy shocks

This table reports presents the estimated response of unexpected excess bond returns $\left(\tilde{x}_{n}^{R M P}\right)$ and the two news components (interest rate news, $\tilde{x}_{y}^{R M P}$, and discount rate news, $\tilde{x}_{x}^{R M P}$ ) to the Romer and Romer (2004) monetary policy shocks $(R M P)$. News components are extracted from a $\operatorname{VAR}(1)$ model where the state vector is given by $\left[x_{n, t+1}, d e f_{t+1}, \operatorname{term}_{t+1}, y_{t+1}\right]^{\prime}$, where $x_{n}$ denotes excess returns on the Barclays corporate bond index with average maturity $n$; def denotes the default spread; term is the term spread; and $y$ denotes the continuously compounded one-month Treasury bill rate. The Barclays indices represent portfolios of long-term $(L)$ and intermediate $(I)$ maturity corporate bonds with AAA, AA, and A ratings. The sample period is 1989.02-2007.07. The standard errors reported in parentheses are computed using the delta method. ${ }^{*},{ }^{* *}$, and ${ }^{* * *}$ denote statistical significance at the $10 \%, 5 \%$, and $1 \%$ levels, respectively.

\begin{tabular}{lcccccc}
\hline \hline & $A A A^{L}$ & $A A^{L}$ & $A^{L}$ & $A A A^{I}$ & $A A^{I}$ & $A^{I}$ \\
\hline$\tilde{x}_{n}^{R M P}$ & $-1.88^{* * *}$ & $-2.09^{* * *}$ & $-2.45^{* * *}$ & $-0.77^{* * *}$ & $-0.87^{* * *}$ & $-1.10^{* * *}$ \\
& $(0.44)$ & $(0.46)$ & $(0.48)$ & $(0.22)$ & $(0.23)$ & $(0.23)$ \\
$\tilde{x}_{y}^{R M P}$ & 0.33 & 0.21 & 0.70 & -0.20 & -0.25 & 0.03 \\
& $(0.39)$ & $(0.49)$ & $(0.45)$ & $(0.39)$ & $(0.48)$ & $(0.40))$ \\
$\tilde{x}_{x}^{R M P}$ & $1.56^{* * *}$ & $1.87^{* * *}$ & $1.74^{* * *}$ & $0.97^{* * *}$ & $1.12^{* *}$ & $1.07^{* * *}$ \\
& $(0.50)$ & $(0.58)$ & $(0.52)$ & $(0.38)$ & $(0.46)$ & $(0.39)$ \\
\hline \hline
\end{tabular}


Table A.9: VAR-based response of unexpected excess bond returns to monetary policy shocks: risk premium-adjusted monetary policy shocks

This table reports presents the estimated response of unexpected excess bond returns $\left(\tilde{x}_{n}^{A M P}\right)$ and the two news components (interest rate news, $\tilde{x}_{y}^{A M P}$, and discount rate news, $\tilde{x}_{x}^{A M P}$ ) to risk premium-adjusted monetary policy shocks $(A M P)$. News components are extracted from a $\operatorname{VAR}(1)$ model where the state vector is given by $\left[x_{n, t+1}, d e f_{t+1}, t e r m_{t+1}, y_{t+1}\right]^{\prime}$, where $x_{n}$ denotes excess returns on the Barclays corporate bond index with average maturity $n$; def denotes the default spread; term is the term spread; and $y$ denotes the continuously compounded one-month Treasury bill rate. The Barclays indices represent portfolios of long-term $(L)$ and intermediate $(I)$ maturity corporate bonds with AAA, AA, and A ratings. The sample period is 1989.02-2007.07. The standard errors reported in parentheses are computed using the delta method. ${ }^{*},{ }^{* *}$, and ${ }^{* * *}$ denote statistical significance at the $10 \%, 5 \%$, and $1 \%$ levels, respectively.

\begin{tabular}{lcccccc}
\hline \hline & $A A A^{L}$ & $A A^{L}$ & $A^{L}$ & $A A A^{I}$ & $A A^{I}$ & $A^{I}$ \\
\hline$\tilde{x}_{n}^{A M P}$ & $-3.99^{* * *}$ & $-4.07^{* * *}$ & $-4.89^{* * *}$ & $-2.40^{* * *}$ & $-2.67^{* * *}$ & $-2.99^{* * *}$ \\
& $(0.43)$ & $(0.44)$ & $(0.44)$ & $(0.21)$ & $(0.21)$ & $(0.22)$ \\
$\tilde{x}_{y}^{A M P}$ & 0.20 & 0.05 & 0.90 & 0.25 & 0.45 & 0.91 \\
& $(0.64)$ & $(0.71)$ & $(0.63)$ & $(0.56)$ & $(0.65)$ & $(0.67)$ \\
$\tilde{x}_{x}^{A M P}$ & $3.79^{* * *}$ & $4.02^{* * *}$ & $3.99^{* * *}$ & $2.16^{* * *}$ & $2.22^{* * *}$ & $2.08^{* * *}$ \\
& $(0.54)$ & $(0.63)$ & $(0.55)$ & $(0.46)$ & $(0.55)$ & $(0.56)$ \\
\hline \hline
\end{tabular}

